\title{
Las cláusulas abusivas en los contratos de adhesión en el derecho colombiano*
}

\section{CAMILO POSADA TORRES ${ }^{*}$}

Resumen: En los contratos de adhesión su contenido es impuesto por el predisponente al adherente sin ninguna posibilidad de ser discutido ni modificado, incrementándose así el riesgo de alteración del equilibrio jurídico del mismo, mediante la inclusión de cláusulas abusivas en su contenido. En el ordenamiento jurídico colombiano se han identificado diversas clases de cláusulas que implican beneficios desmedidos, injustos e injustificados a favor del predisponente, y que colocan al adherente en una situación de mayor debilidad. La teoría de las cláusulas abusivas surge como un mecanismo para recomponer el equilibrio jurídico roto, existiendo diferentes criterios para su aplicación en el derecho colombiano, según se trate de contratos de adhesión con consumidores o de contratos de adhesión entre empresarios (o no consumidores).

Palabras clave: buena fe contractual, contrato de adhesión, equilibrio jurídico del contrato, parte fuerte, predisponente, parte débil, consumidor, adherente, cláusulas abusivas.

Fecha de recepción: 13 de abril de 2015. Fecha de aceptación: 3 I de agosto de 2015.

Para citar el artículo: C. Posada Torres, "Las cláusulas abusivas en los contratos de adhesión en el derecho colombiano", Revista de Derecho Privado, Universidad Externado de Colombia, n. ${ }^{\circ} 29$, julio-diciembre de 2015, pp. I4I-I 82. DOI: http://dx.doi.org/IO.I860I/oI 234366. n29.07

** Abogado de la Universidad Colegio Mayor de Nuestra Señora del Rosario, especialista en Derecho Contractual y en Derecho Comercial de la misma universidad, magíster en Derecho Comercial de la Universidad Externado de Colombia, profesor de Contratos y Cláusulas Abusivas en la Universidad Colegio Mayor de Nuestra Señora del Rosario, Colombia. Contacto: camilo.posada@urosario.edu.co; posadacamilo@yahoo.es 


\section{Unfair contractual terms in standard form contracts under Colombian Law}

Aвstract: The content of adhesion contracts is imposed by the proposing party to the adhering party without the possibility of being discussed or modified, thus increasing the risk of altering it's legal balance by the inclusion of unfair terms. For example, in the Colombian legal system different kinds of clauses involving excessive, unfair and unjustified benefits have been identified which benefit the proposing party and that place to the adhering party in a situation of greater weakness. Consequently, the theory of unfair clauses has arisen as a method of repairing this legal imbalance. Different criteria exist for applying this theory in Colombian law, such as in the case of adhesion contracts with consumers or adhesion contracts between employers (or non-consumers).

Keywords: Good faith, adhesion contract, legal balance of the contract, strong party, proponent, weak party, consumer, adherent, abusive terms.

Sumario: Introducción. I. El contrato de adhesión. A. Concepto de contrato de adhesión. B. Partes en el contrato de adhesión. ir. Teoría de las cláusulas abusivas. A. Origen de la teoría de las cláusulas abusivas. B. Fundamento de la teoría de las cláusulas abusivas. C.Ámbito de aplicación de la teoría de las cláusulas abusivas. D. Concepto y características generales de las cláusulas abusivas. III. Tipología de cláusulas abusivas. A. Cláusulas que limitan o exoneran la responsabilidad del predisponente respecto de las obligaciones que le corresponden por ley. B. Cláusulas que implican la renuncia de los derechos del adherente que le corresponden por ley. C. Cláusulas que trasladan al adherente o a un tercero que no sea parte en el contrato la responsabilidad del predisponente. D. Cláusulas que establecen que el predisponente no reintegrará el precio recibido en caso de ejecución total o parcial del objeto del contrato. E. Cláusulas que imponen el pago de intereses no autorizados legalmente. F. Cláusulas que obligan al adherente a acudir a la justicia arbitral. G. Cláusulas que restringen o eliminan la facultad del adherente para hacer efectivas frente al predisponente las garantías del producto. Conclusiones. Bibliografía.

\section{Introducción}

Los contratos de adhesión, como instrumentos jurídicos, cumplen actualmente dos finalidades económicas de suma trascendencia para el desarrollo de la economía: por una parte, viabilizan el intercambio masivo de bienes y/o servicios, haciendo más rápida y expedita la circulación de la riqueza en el tráfico; por otra parte, se erigen como una estrategia de manejo de costos de los empresarios 
orientada a la eficiencia económica. Dentro de este contexto, los empresarios predisponentes suelen utilizar en sus contratos ciertas cláusulas que pueden llegar a ser abusivas, sin importar que eventualmente agraven la constitutiva posición asimétrica de los adherentes, quienes ya de suyo se ven impuesto un contenido predispuesto. Es por esta razón que la ley autoriza la intervención del Estado en estas relaciones jurídicas, para garantizar la igualdad jurídica de las partes mediante una regulación especial orientada a la protección de las partes débiles de cara a los perjuicios que de otra manera pudieran sufrir por virtud de la insatisfacción de sus intereses individuales y a la limitación arbitraria de sus derechos.

En derecho colombiano existe solamente un régimen de protección especial para la parte débil que ostenta la calidad de consumidor, de manera que cabe preguntarse: ¿cuál sería el régimen de protección para los adherentes que no ostentan la calidad de consumidor en el marco de los contratos de adhesión entre empresarios? ¿Cuáles son los criterios que han desarrollado la doctrina y la jurisprudencia (judicial y arbitral) que deben tenerse en cuenta para determinar la abusividad de una cláusula tanto en los contratos de adhesión celebrados entre empresarios (o no consumidores) como en los contratos de adhesión entre empresarios y consumidores?

\section{El contrato de adhesión}

\section{A. Concepto de contrato de adhesión}

La doctrina ha definido el contrato de adhesión como aquel acuerdo de voluntades por medio del cual uno de los contratantes, denominado predisponente, impone al otro, llamado adherente, el contenido del contrato sin ninguna posibilidad de discutirlo ni de modificarlo, contando únicamente con la facultad de decidir libremente si contrata o no bajo el clausulado ofrecido, dentro de un esquema de "lo toma o lo deja" I. En derecho colombiano, ni el Código Civil ni el Código de Comercio definen el concepto de contrato de adhesión, aunque podemos encontrar una definición en el Estatuto del Consumidor, según el cual se trata de "aquel en el que las cláusulas son dispuestas por el productor o proveedor, de manera que el consumidor no puede modificarlas, ni puede hacer otra cosa que aceptarlas o rechazarlas" 2 .

I Christian Larroumet, Teoría general del contrato, vol. i, reimpr. 2. ${ }^{a}$ ed., trad. de Jorge Guerrero, Temis, Bogotá, I999, p. 207: “el elemento característico del contrato de adhesión consiste en que las disposiciones contractuales no son susceptibles de discutirse entre las partes; ya que una de estas las comunica a la otra, quien solo puede dar su consentimiento en bloque o negarse a celebrar el contrato si tales disposiciones no le convienen”.

2 Ley I480 de 201 I, art. 5 , num. 4 . 
De las definiciones anteriores observamos, en primer lugar, que sobresale el carácter asimétrico de los contratos de adhesión, el cual se concreta en la desigualdad que existe entre las partes con relación a su poder contractual ${ }^{3}$. Dicha desigualdad se manifiesta, por una parte, en los especiales y profundos conocimientos que ha adquirido el predisponente como consecuencia del desarrollo de su actividad económica 4 , y de los cuales normalmente no dispone el adherente; $y$, por otra parte, en el poder que tiene el predisponente en razón de su posición económica en el mercado5 ${ }^{5}$.

Ahora bien, ante la desigualdad de los contratantes que entrañan los contratos de adhesión, el ordenamiento jurídico no toma una postura radical basada en su prohibición para proteger los derechos de los adherentes, porque de hacerlo, frenaría la celeridad y la agilidad de las transacciones propias de nuestra época, generando un efecto negativo para el desarrollo económico del conglomerado social ${ }^{6}$; de manera que opta más bien por permitirlos, pero sometiéndolos a una serie de controles dirigidos a evitar los abusos que podrían derivarse para

3 Vincenzo Roppo, "Del contrato con el consumidor a los contratos asimétricos: perspectivas del derecho contractual europeo", Revista de Derecho Privado, n. ${ }^{\circ}$ 2o, enero-junio, Universidad Externado de Colombia, 20 I I, I 77: "los contratos asimétricos son relaciones contractuales entre una empresa dominante y otro sujeto del mercado (sea o no un consumidor), que se encuentra en condiciones de desigualdad en cuanto a su poder contractual, en razón de su posición objetiva en el mercado".

4 Corte Constitucional, Sala Plena, sentencia C-749 del 2 I de octubre de 2009, exp. D-7686, M.P.: Luis Ernesto Vargas Silva: "De un lado, el avance de la ciencia y la tecnología en la sociedad contemporánea y, sobre todo, la especialización en los procesos productivos, ocasiona grandes asimetrías de información entre los sujetos que concurren al intercambio de bienes y servicios. En efecto, los consumidores suelen carecer del conocimiento y experticia suficientes para discernir acerca de los aspectos técnicos que definen la calidad de los productos, incluso aquellos de consumo diario". Cfr. Jorge Mosset Iturraspe, "Introducción al derecho del consumidor", Revista de Derecho Privado y Comunitario, n. ${ }^{\circ}$, Consumidores, Buenos Aires, Rubinzal-Culzoni, I I.

5 Corte Constitucional, Sala Plena, sentencia C-749 de 2009, exp. D-7686, M.P.: Luis Ernesto Vargas Silva: "los fabricantes y comercializadores son, en la mayoría de ocasiones, conglomerados empresariales que tienen a su disposición infraestructuras que, a manera de economías de escala, participan en el mercado económico e, inclusive, concurren ante las autoridades administrativas y judiciales con evidentes ventajas, habida cuenta de la disponibilidad de recursos, asesorías profesionales permanentes de primer nivel y conocimiento acerca del funcionamiento de las instancias de resolución de conflictos jurídicos, derivado de la condición de litigantes recurrentes". Cfr. José Antonio Ballesteros Garrido, Las condiciones generales de los contratos y el principio de la autonomía de la voluntad, tesis doctoral, dir. Julio Carbajo González, Bosch, Barcelona, I999, 69.

6 Corte Constitucional, Sala Sexta de Revisión, sentencia T-5 I 7 del 7 de julio de 2006, referencia T-I308 I 2 5, M.P.: Marco Gerardo Monroy Cabra: "la circulación de bienes, distribución y movilización de la riqueza, derivada de la garantía de la propiedad privada, asociativa y solidaria (C.P., art. 58) sería impensable sin recurrir al contrato". Cfr. Diego F. SAlazar, "Asimetrías de información y análisis económico de los contratos de adhesión: una reflexión teórica sobre el ejercicio de la libertad contractual", Revista de derecho privado n. ${ }^{\circ} 37$, Universidad de los Andes, Facultad de Derecho, Bogotá, 2006, 5. 
los intereses de los adherentes y en beneficio exclusivo de los predisponentes? Por medio de tales controles, el legislador restringe la autonomía privada del predisponente con el establecimiento de un conjunto de normas imperativas dirigidas a garantizar la presencia en los contratos de adhesión de un contenido mínimo en protección de los derechos de los adherentes ${ }^{8}$; impone así unas cargas a los predisponentes, como son el deber de información ${ }^{9}$, el deber de buena $\mathrm{fe}^{\mathrm{IO}}$, entre otros; somete a un control administrativo previo $^{11}{ }^{\text {o }}$ posterior ${ }^{12}$, según el caso, el contenido de los contratos de adhesión, con el fin de evitar clausulados

7 Corte Constitucional, Sala Sexta de Revisión, sentencia T-5 I 7 de 2006, cit.: "no será posible lograr la vigencia de un orden justo si la categoría del contrato, que por sí sola responde de una porción significativa de las relaciones sociales, no es examinada por el juez y asumida por los particulares con un mínimo criterio de justicia sustancial (C.P., arts. 2 y I 3 )".

8 Joaquín Ataz López y José Ramón Salelles Climent, "La libertad contractual y sus límites", en Tratado de contratos, t. I, dir. Rodrigo Bercovitz Rodríguez-Cano, Valencia, Tirant lo Blanch, 2009, p. I49: "El primer límite a la libertad contractual es la ley [...]. [L]a referencia a la ley [...] va dirigida, en primer lugar, a las normas del Derecho Imperativo [...]. Por norma imperativa se entiende aquélla caracterizada por ser inderogable por la voluntad de las partes, es decir: aquellas normas en las que no es posible la exclusión voluntaria de la ley aplicable [...]. Las leyes limitativas de la autonomía privada podrán serlo bien por proteger un interés general o público, bien por proteger a alguno de los contratantes, identificados por la ley como merecedor de protección, bien por proteger el interés de terceros".

9 Ernesto Rengifo García, "Deber precontractual de información y las condiciones generales de contratación", Revista de la Academia Colombiana de Jurisprudencia, n. ${ }^{\circ} 327$, Bogotá, diciembre de 2004, 9i: "en razón de esa asimetría de poder y de esa asimetría en la información es que el deber de información ha despuntado trascendental en aquellos contratos en donde el desequilibrio de poder contractual es evidente. Se insiste, se debe informar todo aquello que contribuya a fortalecer el consentimiento, y más acendrado será el deber cuando exista una parte débil en la relación jurídica. Una información adecuada y suficiente de parte del oferente de un producto o servicio viene, en cierta medida, a equilibrar la asimetría de información que existe".

io Carlos Alberto Soto Coaguila y Jorge Mosset Iturraspe, El contrato en una economía de

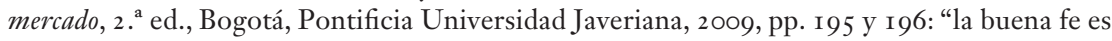
mucho más que lo opuesto a la mala fe; es creadora de importantes deberes, que nacen para todos los que se relacionan con otras personas".

i i Rubén S. Stiglitz. "Contrato de consumo y cláusulas abusivas”, Universitas n. ${ }^{\circ}$ 93, Pontificia Universidad Javeriana, Facultad de Ciencias Jurídicas, Bogotá, I997, pp. 395 y 396: "Francia es paradigma de un sistema que tiene su origen en el art. 37 de la Ley del io de enero de i 978 . Establece un control administrativo previo sobre las cláusulas abusivas que, en lo esencial, consiste en la existencia de una 'Comisión de cláusulas abusivas', presidida por el ministro del Consumo quien conocerá 'de los modelos de contratos habitualmente propuestos por los profesionales a los no profesionales o consumidores'. Dicha comisión se halla encargada en la búsqueda o investigación de si los referidos modelos contienen cláusulas que pueden presentar un carácter abusivo".

i 2 Verónica María Salazar Echeverri, "El control de las cláusulas abusivas en los contratos de adhesión con consumidores", Opinión furídica, vol. Io, n. ${ }^{\circ}$ 20, Medellín, 201 I, p. I 37: "El control administrativo también se puede presentar como 'posterior', cuando las entidades gubernamentales tienen facultades sancionatorias con respecto a aquellos contratantes que predispongan cláusulas abusivas". 
abusivos que vulneren los derechos de los adherentes; y establece un control judicial $^{\mathrm{I} 3}$ de los mismos.

En segundo lugar, de las definiciones antes referidas sobresale asimismo la limitación a la libertad del adherente para discutir y modificar el contenido del contrato que le ha sido ofrecido ${ }^{\mathrm{I}}$. En nuestro concepto, este límite se justifica en la restricción de la autonomía privada del predisponente por parte de la ley, de manera que él no goza de plena libertad para diseñar y configurar el contenido de sus contratos de adhesión, por cuanto existen unas normas legales de carácter imperativo que le imponen unos contenidos mínimos con el propósito de que no se vulneren los derechos de los adherentes ${ }^{15}$. Desde esta perspectiva, en derecho colombiano existe la llamada "lista negra" ${ }^{\text {'6 }}$, por medio de la cual el legislador prohíbe al predisponente incluir cualquiera de las cláusulas en ellas enumeradas, pues el simple hecho de incorporarlas en el contenido de tales contratos significaría un beneficio injustificado para el predisponente; en efecto, por un lado, este reafirmaría su posición de superioridad contractual ratificando la desigualdad existente entre las partes ${ }^{17}$, y por otro lado, se produciría una

I 3 Jorge Suescún Melo, Derecho privado, estudios de derecho civil y comercial contemporáneo, t. II, $2 .^{\text {a }}$ reimpr., Legis, Bogotá, 2005 , pp. I 94 y 233: "en el derecho anglosajón se permite al juez controlar las disposiciones de cualquier contrato, sea o no de adhesión, para determinar si son desleales y, por ende, para descartarlas. [...] [E]l control judicial [...] está enderezado a hacer observar la buena fe y a restablecer la mutua confianza de los contratantes, de tal manera que de la ejecución de las prestaciones que se desprenden del negocio las partes logren las metas jurídicas y económicas que razonablemente contemplaron al estructurar y perfeccionar el contrato. Con este propósito los jueces descartan la aplicación de las cláusulas en cuestión, y las privan de efectos prácticos, toda vez que han de tenerse por no escritas".

I 4 Laudo arbitral en derecho, I 5 de noviembre de 2002, Centro de Arbitraje y Conciliación de la Cámara de Comercio de Bogotá, árbitros: Francisco Morales Casas (presidente), Sergio Muñoz Laverde y Roberto Uribe Ricaurte, demandante: Adriana María Calderón Palacio, demandado: Cafesalud Medicina Prepagada S.A.: "quien pretende contratar con quien ha elaborado los términos y condiciones del contrato no tiene la posibilidad de discutirlos con éxito, de suerte que se puedan introducir modificaciones o ajustes. [...] [L]o que caracteriza esencialmente al contrato por adhesión radica [...] en el hecho de verse imposibilitado en la práctica, quien contrata con la parte que extiende o dicta las condiciones del negocio, dada la superioridad respecto del poder de negociación que tiene este frente a aquel, de discutir eficazmente los contenidos negociales predispuestos".

I 5 Ernesto Rengifo García, Del abuso del derecho al abuso de la posición dominante, reimpr. 2. ${ }^{a}$ ed., Bogotá, Universidad Externado de Colombia, 2009, pp. i 89 y i9o: "el no abusar cuando se tiene el poder de configuración del contrato puede ser entendido como un límite a la autonomía privada. El que introduce las condiciones generales en el contrato no puede establecer lo que él quiera, sino que está obligado a establecer, según un criterio equitativo, la regulación que se le ha confiado adoptar".

i6 Carlos Alberto Soto, "La transformación del contrato: del contrato negociado al contrato predispuesto", en Instituciones de Derecho Privado I, Contratación contemporánea, Teoría general y principios, Lima y Bogotá, Palestra y Temis, 2000, p. 423: "una 'lista negra' consiste en la enumeración taxativa de una relación, cerrada o abierta, de supuestos en los que determinadas cláusulas o estipulaciones contractuales serían declaradas nulas". Cfr. Ley I480 de 20 I I, art. 43.

i Camilo Posada Torres, El equilibrio contractual en los contratos de adhesión, Grupo editorial 
vulneración de los derechos de los adherentes como partes débiles que son en esta clase de contratación por adhesión.

Finalmente, en las definiciones en estudio sobresale la reducción de la autonomía privada del adherente, la cual está circunscrita únicamente a elegir si contrata o no bajo el clausulado ofrecido por el predisponente. De esta manera, tanto la doctrina ${ }^{18}$ como la jurisprudencia ${ }^{19}$ reconocen que la libertad contractual del adherente se encuentra limitada a decidir si contrata o no bajo el contenido negocial ofrecido por el predisponente. Así las cosas, observamos la importancia del derecho de la competencia económica, no solo para velar por un mercado sin distorsiones, en el cual los empresarios puedan competir por una clientela y por conquistar nuevos mercados sin recurrir a comportamientos desleales, sino también como la vía más eficaz para garantizar la libertad contractual de los adherentes; esto último por medio de una pluralidad de opciones presentes en el mercado, entre las cuales poder elegir con quién contratar la adquisición de bienes y/o la prestación de servicios requeridos. Además, en virtud de la protección brindada a los adherentes por el derecho de la competencia, los empresarios se ven compelidos a competir, no solo por ofrecer bienes y/o servicios de mejor calidad, precio y garantías, sino también por ofrecer los clausulados más justos y que brinden una mayor protección a los derechos de aquellos ${ }^{20}$.

Ibáñez, Bogotá, 2014, p. I95: "las cláusulas abusivas que se insertan en las listas negras son las utilizadas con mayor regularidad y, por ser consideradas como irrazonables y perjudiciales para los intereses del adherente (o consumidor), la ley no admite ninguna posibilidad de ser valoradas posteriormente en cuanto a su abusividad, toda vez que el legislador ya ha hecho una valoración previa sobre la dañosidad de las mismas significando su poderío para romper el equilibrio jurídico del contrato".

I 8 José Luis De Los Mozos, El contrato y sus transformaciones, Estudios de derecho civil, obligaciones y contratos, Libro bomenaje a Fernando Hinestrosa, 40 años de rectoría I963-2003, t. I, Bogotá, Universidad Externado de Colombia, 2003, p. 369: "la aparición [...] del fenómeno de los llamados contratos de adhesión [...]. [N]o se trataba de la expresión de una voluntad tácita o presunta, sino de la imposición por una de las partes, a la otra, de las condiciones del contrato, lo que anulaba por completo su libertad y, en definitiva, el que pudiera formarse una verdadera voluntad contractual, al faltar la situación de igualdad en que ambas partes deben encontrarse".

I9 Corte Constitucional, Sala Plena, sentencia C-075 de 2006, exp. D-5747, M.P.: Rodrigo Escobar Gil: "las cláusulas que regulan el contrato, por lo general, son redactadas previa y unilateralmente por la empresa de servicios públicos, sin ofrecerle a los usuarios la posibilidad de deliberar y discutir sobre el contenido de las mismas".

20 Corte Constitucional, Sala Plena, sentencia C-6 6 de 200 I, exp. D-32 79, M.P.: Rodrigo Escobar Gil: "el elemento característico de la libre competencia es la tensión que se presenta entre los intereses opuestos de los agentes participantes en el mercado, cuyo mantenimiento exige la garantía de ciertas libertades básicas, que algunos doctrinantes han condensado en: a) la necesidad [de] que los agentes del mercado puedan ejercer una actividad económica libre, con las excepciones y restricciones que por ley mantiene el Estado sobre determinadas actividades; b) la libertad de los agentes competidores para ofrecer, en el marco de la ley, las condiciones y ventajas comerciales que estimen oportunas, y c) la libertad de los consumidores o usuarios para contratar con cualquiera de los agentes oferentes, los bienes y servicios que requieran". 


\section{B. Partes en el contrato de adhesión}

Las partes en el contrato de adhesión son: el predisponente y el adherente.

El predisponente es una persona (natural o jurídica) que ostenta la calidad de empresario, la cual revela una posición de superioridad contractual frente al adherente que le permite diseñar el arquetipo negocial y establecer las reglas por medio de las cuales se regirán todas las relaciones jurídicas nacidas de los contratos de adhesión que celebre individual o masivamente en el mercado, para realizar todas las operaciones y transacciones en desarrollo de su actividad económica ${ }^{2}$.

Nos preguntamos ahora si toda persona que ostenta la calidad de parte fuerte en el contrato de adhesión también ostenta necesariamente una posición dominante en el mercado, respecto de lo cual debemos responder que en principio no, porque el concepto de parte fuerte contractual está referido solo a un estado de superioridad jurídica en el marco del contrato que le permite a una parte establecer unilateralmente el contenido del mismo. Mientras que el concepto de posición dominante en el mercado hace referencia a un estado económico en el que "un agente económico puede actuar independientemente de competidores y consumidores, [esto es] cuando una persona puede abstraerse de la competencia efectiva, influyendo preponderantemente en el mercado, es decir, actúa sin tener en cuenta a otros agentes económicos" ${ }^{22}$; en este caso, la posición dominante constituye una recompensa a la eficiencia económica por él demostrada y que le ha permitido eliminar competidores, dentro de la concepción de un sistema económico capitalista, siendo únicamente ilegal el abuso de dicha posición ${ }^{23}$.

En el otro extremo de la relación jurídica encontramos al adherente, entendido como la persona (natural o jurídica) que contrata con el predisponente la adquisición de bienes y/o la prestación de servicios requeridos para la satisfacción de sus necesidades personales, familiares o domésticas, como destinatario final

2 I Corte Suprema de Justicia, Sala de Casación Civil, sentencia del I 4 de diciembre de 20 I I, ref. C-i ioor 3 iozor 4200 i-or 489-or, M.P.: Jaime Alberto Arrubla Paucar: "Los bancos [...] ejercen una posición dominante en las operaciones activas y pasivas que realizan con los usuarios de sus servicios, la cual se concreta en la hegemonía que pueden ejercer para imponer el contenido del contrato, en la determinación unilateral de su configuración y en la posterior administración de su ejecución”.

22 Alfonso Miranda Londoño, "Abuso de posición dominante: perspectivas de aplicación en Colombia a la luz del derecho comparado", Revista del Centro de Estudios del Derecho de la Competencia (CEDEC), Pontificia Universidad Javeriana, Bogotá, I997, p. 52: "La posición dominante en el mercado se distingue esencialmente por la capacidad que tiene una empresa o persona, para determinar en forma directa o indirecta el precio, calidad, cantidades y demás condiciones dentro de un mercado". Cfr. Mauricio Velandia, Derecho de la competencia y el consumo, Bogotá, Universidad Externado de Colombia, 2008, p. I 26.

23 Velandia. Derecho de la competencia y el consumo, cit., p. I 28. 
de los mismos, o para incorporarlos en su proceso de producción o transformación, o simplemente para comercializarlos ${ }^{24}$. De esta manera, el adherente se identifica como la parte débil en los contratos de adhesión, y básicamente puede ser de dos clases: consumidor y no consumidor (o empresario débil $)^{25}$.

Así las cosas, el hecho de ostentar alguna de estas dos calidades (consumidor o no consumidor) determina el régimen legal aplicable para la protección de los derechos de la parte débil en el contrato de adhesión. De esta manera, si ella ostenta la calidad de consumidor quedará sometida al régimen especial establecido por el Estatuto del Consumidor, mientras que si no ostenta dicha calidad -por adquirir los bienes y/o servicios con el propósito de incorporarlos en sus procesos productivos, de transformación y comercialización de bienes o prestación de servicios- no gozará del régimen de protección especial mencionado, quedando sometida a la protección brindada por las normas jurídicas de carácter general.

\section{Teoría de las cláusulas abusivas}

\section{A. Origen de la teoría de las cláusulas abusivas}

El primer antecedente de la teoría de las cláusulas abusivas aprece con la Revolución Francesa, gracias a la cual se reconoció la libertad individual, manifestada en la libertad jurídica o autonomía de la voluntad. Fue así como los ordenamientos jurídicos de finales del siglo xix reconocieron a las personas tanto la facultad de autorregular sus propios intereses -dentro de unos límites amplísimos, a fin de restringir al mínimo la intervención del Estado en las relaciones jurídicas entre particulares- como la facultad de contraer válida y voluntariamente obligaciones ${ }^{26}$. De esta manera, el contrato se convirtió en el instrumento jurídico por medio del cual las personas ejercen su libertad jurídica (o autonomía de la voluntad), fijando las reglas a las que se someterán voluntariamente con el propósito de

24 Posada Torres. El equilibrio contractual en los contratos de adhesión, cit., pp. 62 y 63: "no podemos desconocer que el concepto de parte débil no sólo abarca al consumidor, sino que por ser un concepto amplio también incluye a los empresarios que celebran contratos de adhesión individuales con empresarios que ostentan una posición de dominio contractual, en los cuales, generalmente, el empresario predisponente impone sus políticas de contratación al empresario débil, que en palabras de Roppo son los llamados contratos 'business to business (B2 B)'”.

25 Jorge Mosset Iturraspe. Introducción al derecho del consumidor, cit., i 8: "En ciertas situaciones se ha reconocido la calidad de consumidor a un profesional, frente a otro profesional proveedor, pero exigiendo que: a) no se trate de un especialista, y b) que entre uno y otro medie una fuerte diferencia en orden a la dominación y al poder de negociación”. Cfr. Corte Constitucional, Sala Plena, sentencia C-I I4 I de 2000, M.P.: Eduardo Cifuentes Muñoz.

26 Carlos Gustavo Vallespinos, El contrato por adhesión a condiciones generales, cit., p. 86: "El querer individual se erigió en el principio fundamental de la vida social y económica trascendiendo al plano político no sólo por reducir la función del Estado a la protección de las voluntades sino también por postergarlo ante la concepción de una voluntad superior y anterior a él”. 
dirigir su comportamiento hacia la satisfacción de sus intereses individuales ${ }^{27} \mathrm{y}$, como consecuencia de ello, adquiriendo derechos y contrayendo obligaciones de forma voluntaria. Tales reglas de libre elección resultaron igualmente vinculantes con fuerza de ley en virtud del principio pacta sunt servanda ${ }^{28}$.

Con la Revolución Industrial, que se gestó a partir de mediados del siglo XVIII, los empresarios aplicaron la ciencia tanto a los modos de producción con el propósito de ofrecer más productos (bienes y servicios) en el mercado, para satisfacer las crecientes necesidades de las masas ${ }^{29}$ - como a los medios de transporte -lo que permitió acercar los diferentes lugares y significó un estímulo para el comercio más allá de las fronteras nacionales-3․ Estos desarrollos estaban dirigidos a la consecución por parte de los empresarios de un fin estrictamente económico: la acumulación de riquezas. Se persiguió así la elaboración de estrategias orientadas a la disminución de costos de producción ${ }^{3 \mathrm{I}}$, y en este contexto, los abusos cometidos contra la clase trabajadora y la producción en masa de bienes con desmedro de la calidad fueron apenas dos de las estrategias implementadas para multiplicar las ganancias ${ }^{32}$.

27 C. Massimo Bianca. Derecho civil, 3, El contrato, trad. Fernando Hinestrosa y Édgar Cortés, Bogotá, Universidad Externado de Colombia, 2007, p. 28: "La definición de contrato como autorregulación, formulada en términos de abierta oposición a la denominada teoría subjetiva (n. ${ }^{\circ}$ ), integra la noción de contrato remitiéndose al momento objetivo, que es inexcusable, o sea a la 'disposición' o a la 'regla' que las partes generan mediante su acuerdo".

28 Fernando Hinestrosa, "De los principios generales del derecho a los principios generales del contrato", Revista de Derecho Privado n. ${ }^{\circ}$, Universidad Externado de Colombia, 200o, 20, habla de "la elementalidad y universalidad del principio pacta sunt servanda, base del tráfico jurídico, fundamento de la seguridad, que muestra la naturaleza compromisoria del contrato". Cfr. Soto Coaguila y Mosset Iturraspe, El contrato en una economía de mercado, cit., p. i 89.

29 M.I. Mijailov. La revolución industrial, ı. a reimpr., Bogotá, Panamericana, 20 I I, p. 43: "La invención de la máquina de vapor [...] fue el resultado de los conocimientos prácticos; sólo puede [sic] efectuarla un hombre que, además de la habilidad práctica, contase con grandes conocimientos en la esfera de las ciencias exactas. La invención y la aplicación en gran escala de la máquina de vapor fue la base de la gran industria; las máquinas pudieron existir antes de la invención de la de vapor, pero no pudo haber producción mecánica”.

30 Delgado de Cantú, Historia universal, de la era de las revoluciones al mundo globalizado, cit., p. 4I: "La invención del ferrocarril y la mejora de los caminos carreteros, así como la utilización de barcos de vapor, fueron de gran importancia para impulsar el comercio, interno y externo, de la nueva producción en creciente demanda".

3 I Ballesteros Garrido, Las condiciones generales de los contratos y el principio de la autonomía de la voluntad, cit., p. 25: "La Revolución industrial trajo consigo la aparición de grandes y poderosas empresas con capacidad de producir bienes en serie, en forma masiva. El incremento de la producción, por el paso de la fabricación artesanal a la industrial, permite una importante reducción de los precios, por lo que podrán ser adquiridos por un sector más amplio de la sociedad".

32 Hellbroner, La formación de la sociedad económica, cit., p. I 59: "En el mercado, el que obtenía la ventaja en los costos y el correspondiente aumento de ganancias era precisamente aquel empresario que poseía alguna innovación para bajar los costos. Más aún, una vez que uno de los primeros explotadores de un determinado campo alcanzaba una ventaja técnica, la competencia obligaba rápidamente a los otros explotadores de ese campo a ponerse a la misma altura 
En el marco descrito, los empresarios, en desarrollo de la autonomía de la voluntad a ellos reconocida, comenzaron a elaborar contratos con contenidos uniformes para vender los bienes y prestar los servicios producidos o disponibles masivamente, a todas las personas que los demandaran para satisfacer sus necesidades o deseos de adquirir ${ }^{33}$. Estos contratos tenían la peculiaridad de ser elaborados por los empresarios para regular de manera uniforme una serie de relaciones jurídicas homogéneas con los adquirentes de sus productos, a quienes se les presentaban como una oferta inmodificable que no admitía discusión alguna, pudiendo solo manifestar su aceptación (decisión de contratar) o su rechazo (decisión de no contratar)34; posteriormente fueron denominados por la doctrina "contratos de adhesión", y se erigieron en instrumento al servicio de los empresarios para incrementar la eficiencia económica mediante la reducción de costos y obtener mayores utilidades ${ }^{35}$.

Ahora bien, mediante los contratos de adhesión los empresarios pudieron cometer toda clase de abusos contra los adquirentes de sus productos y servicios, entre otras razones, por el hecho de contener cláusulas que limitaban su responsabilidad o la excluían del todo; de no otorgar ninguna garantía a los adquirentes sobre sus productos; de reservarse la facultad de modificar y terminar unilateralmente el contrato en cualquier momento y bajo cualquier circunstancia; de este modo, el contrato de adhesión se erigió en un instrumento jurídico que propiciaba la desigualdad de las partes y que velaba únicamente por la satisfacción de los intereses de los empresarios, en perjuicio de los adherentes ${ }^{36}$.

lo más pronto posible. Gran parte de las innovaciones para bajar los costos incluía la adición de maquinaria al proceso de producción y esto, a su vez, apoyaba la formación de capital". Cfr. Felipe de Solá Cañizares, Tratado de derecho comercial comparado, t. i, Barcelona, Montaner y Simón, I963, p. 63. Mijailov. La revolución industrial, cit., 20 I I, p. 88.

33 Eduardo Polo, Protección del contratante débil y condiciones generales de los contratos, Civitas, Madrid, I990, 3 I: "las condiciones generales de contratación nacen como una respuesta jurídica a las necesidades técnicas surgidas de la contratación seriada o en masa típica de la economía capitalista, como un medio de racionalizar y simplificar la capacidad negocial de la empresa a través de fórmulas estereotipadas que permitan la realización idéntica y poco menos que simultánea de centenares o miles de contratos". Cfr. Federico de Castro y Bravo, Las condiciones generales de los contratos y la eficacia de las leyes, 2. ${ }^{\mathrm{a}}$ ed., Madrid, Civitas, I985, p. I 7 .

34 Branca. Instituciones de derecho privado, cit., I978, p. 377: "El contratante que se presenta con sus bellas cláusulas muy preparadas y listas, logra normalmente imponerlas, porque tiene un monopolio de derecho [...], o de hecho [...], o porque las condiciones del mercado [...] le favorecen plenamente. Falta toda esa fase preparatoria [...] que se desarrolla en un estira y afloja, con propuestas, rechazos y negociaciones, y que frecuentemente desemboca en concesiones de una y otra parte; en el caso, uno de los dos no colabora en la formación del contrato, sino que lo sufre".

35 Soto Coaguila y Mosset Iturraspe, El contrato en una economía de mercado, cit., p. i 8o: "la reducción de costos de transacción no implica la 'no utilización' del contrato. Lo que se busca es que la celebración de un contrato [...] sea a un costo mínimo que no encarezca el precio del producto a tal extremo de no contratar o realizar la contratación en forma ineficiente".

36 Federico de Castro y Bravo, Las condiciones generales de los contratos y la eficacia de las leyes, cit., 
Es dentro de este contexto que surge la teoría de las cláusulas abusivas 37 , como un mecanismo que vela por que el contrato se mantenga como un instrumento jurídico para la armonización y realización de los intereses de ambos contratantes, como la herramienta principal establecida por el ordenamiento jurídico para velar por la indemnidad del equilibrio contractual, en especial, en una de sus dimensiones: el equilibrio jurídico del contrato ${ }^{3}{ }^{8}$, protegiendo, como consecuencia, los derechos de las partes débiles ${ }^{39}$.

\section{B. Fundamento de la teoría de las cláusulas abusivas}

Con relación al fundamento jurídico de la teoría de las cláusulas abusivas encontramos que existen dos posiciones al respecto: la primera considera que la teoría de las cláusulas abusivas está edificada sobre la teoría del abuso del derecho, entendido como ejercicio abusivo de la libertad contractual $4^{\circ}$. Es decir, son

p. 20: "una corriente $[\ldots]$ condena por razones de Derecho que las condiciones generales se utilicen como medios para que una clase fortalezca su poder, mediante el despojo de garantías jurídicas, a quienes contratan con uno de sus privilegiados miembros".

37 Camilo Andrés Rodríguez Young, Una aproximación a las cláusulas abusivas, Bogotá, Legis y Universidad del Rosario, 2013 , p. 27 : "la doctrina de las cláusulas abusivas [...] tiene tres propósitos fundamentales que legitiman o justifican su razón de ser: a) Controlar y castigar el ejercicio abusivo de la autonomía privada; b) Proteger a aquella parte del contrato que no ha tenido la posibilidad de participar en la determinación de su contenido o en alguna de sus cláusulas y que, por tanto, se limita a aceptar lo predispuesto por la otra parte, y c) Mantener el equilibrio y la justicia contractual entre las partes".

38 González de Alaiza Cardona y Pertíñez Vílchez, Los contratos de adhesión y la contratación electrónica, cit., 2009, p $5_{5} 8$ : "Otra evidencia es el peligro intrínseco a la utilización de condiciones generales de la contratación, de que el contenido del contrato sea únicamente el reflejo de los intereses negociales de la parte que tiene el poder de predisposición".

39 Bianca. Derecho civil, 3, El contrato, cit., 2007, pp. 416 y 4I 7: "Los intereses protegidos se refieren a la salud, a la seguridad y a la calidad de los productos y servicios, a una información adecuada y a una publicidad correcta, a la educación al consumo, a la corrección, transparencia y equidad en las relaciones contractuales que conciernen a bienes y servicios, a la promoción y al desarrollo de la libre, voluntaria y democrática asociación entre consumidores, a la prestación de servicios públicos según estándares de calidad y eficacia [...]. El abuso del poder contractual también perjudica el mercado cuando se ejercita en las relaciones entre empresarios, pues penaliza las categorías de productores y comerciantes víctimas de tal poder, y altera el libre juego de intercambios e inversiones".

40 Rengifo García, Del abuso del derecho al abuso de la posición dominante, cit., pp. I90 y ig I: "uno de los medios de control al contenido abusivo del contrato ha sido precisamente el abuso del derecho, y más específicamente el abuso del derecho en la libertad de contratar o en el poder de negociación [...]. El abuso del derecho [...] puede provenir de la disposición unilateral de condiciones generales abusivas al ejercitarse el derecho de la libertad de empresa y al concretarse el principio-derecho de la autonomía de la voluntad". Cfr. Corte Suprema de Justicia, Sala de Casación Civil, sentencia del 2 de febrero de 2001 , exp. 5670 , M.P.: Carlos Ignacio Jaramillo Jaramillo. Jorge Hernán Gil Echeverry, "El abuso en las cláusulas contractuales", en Estudios de derecho privado, Liber amicorum en homenaje a Hernando Tapias Rocha, Bogotá, Universidad del Rosario, 2013, p. 239. 
consideradas como abusivas todas las cláusulas, impuestas por el predisponente (parte fuerte) en ejercicio de su libertad contractual al adherente (parte débil), en cuanto alteren, de manera injustificada y en perjuicio de los intereses de la parte débil, el equilibrio jurídico del contrato, por entenderse que la libertad contractual ha sido ejercida de manera abusiva en perjuicio de los intereses del adherente ${ }^{4 \mathrm{I}}$.

Esta primera posición ha sido criticada ${ }^{42}$ porque se considera que la teoría del abuso del derecho fue creada con el único propósito de evitar que el titular de un derecho subjetivo lo ejerciera en perjuicio de los intereses de terceros ${ }^{43}$; de manera que ella "no tiene razón de ser cuando se trata del desarrollo de una actividad en ejercicio de la libertad de actuar" 44 , tal y como sucede con el ejercicio de la libertad contractual del predisponente en virtud de la cual diseña y elabora el contenido del contrato de adhesión que será impuesto a los interesados en adquirir sus productos.

Ahora bien, la segunda posición sostiene que el fundamento de la teoría de las cláusulas abusivas se encuentra en el principio de la buena fe, de acuerdo con el cual los contratantes no solo deben actuar con la intención de no vulnerar ningún interés tutelado por el derecho ${ }^{45}$, sino que adicionalmente, deberán

Laudo arbitral en derecho, proferido el I. ${ }^{\circ}$ de diciembre de 2006, Centro de Arbitraje y Conciliación de la Cámara de Comercio de Bogotá, árbitros: Carlos Esteban Jaramillo Scholls, Juan Pablo Cárdenas Mejía y Gabriel Jaime Arango Restrepo, demandante: Concelular S.A. (en liquidación), demandado: Comunicación Celular S.A., Comcel S.A.: "La aplicación de la teoría del abuso del derecho al campo contractual, específicamente al de la contratación masiva, ha dado lugar a la elaboración de la teoría de las cláusulas abusivas. [...] es precisamente esa desigualdad de las partes la situación que puede dar lugar al ejercicio abusivo del derecho de contratar y del poder de negociación anejo a él, donde se centra la teoría del abuso del derecho en su modalidad de las cláusulas abusivas. Se trata de evitar el abuso de la parte fuerte en la determinación del contenido del contrato".

42 Rezzónico, Contratos con cláusulas predispuestas, cit., pp. 362 y 363. Cfr. Cárdenas Mejía, fusticia y abuso contractual, cit., pp. 7 O I y 702 .

43 Louis Josserand. Del abuso de los derechos y otros ensayos, Temis, Bogotá, i999, 3 y 4: "la teoría de la relatividad [...] lleva a admitir posibles abusos de los derechos, aun de los más sagrados. En esta teoría los derechos, productos sociales, como el mismo derecho objetivo, derivan su origen de la comunidad y de ella reciben su espíritu y finalidad; cada uno se encamina a un fin, del cual no puede el titular desviarlo; están hechos para la sociedad y no la sociedad para ellos; su finalidad está por fuera y por encima de ellos mismos; son, pues, no absolutos, sino relativos; deben ejercerse en el plano de la institución, con arreglo a su espíritu, o de lo contrario seguirán una dirección falsa, y el titular que de ellos haya, no usado, sino abusado, verá comprometida su responsabilidad para con la víctima de esa desviación culpada".

44 Cárdenas Mejía, Justicia y abuso contractual, cit., p. 704.

45 Soto Couguila y Mosset Iturraspe, El contrato en una economía de mercado, cit., pp. 9 I y 92 : "no existe buena fe contractual en el contratante que, teniendo la ventaja de redactar unilateralmente el contenido del contrato, incorpora cláusulas abusivas en perjuicio del futuro contratante que se adhiere a las cláusulas generales de contratación. Por lo tanto, en aplicación de los artículos I 68 y I362, normas de carácter imperativo, los adherentes a contratos predispuestos estarían facultados para solicitar al juez la revisión del contrato, atendiendo a la falta de buena fe con- 
comportarse con lealtad, honestidad, probidad, diligencia y responsabilidad en todas las relaciones jurídicas que establezcan y durante todas las etapas del iter contractus $^{4}$, para que el contrato se erija como el medio idóneo para la satisfacción de los intereses individuales de las partes 47 .

En los contratos de adhesión, el principio de la buena fe impone al predisponente obrar con corrección, lealtad y honestidad tanto en el momento de elaborar y diseñar el contenido predispuesto del mismo como durante su ejecución, para desestimularlo de cara a la eventual comisión de abusos contra el adherente mediante la inclusión de cláusulas que le brinden beneficios jurídicos y/o económicos a costa de la satisfacción de los intereses de la parte débil, o a través del ejercicio abusivo de los derechos que adquiere como consecuencia del perfeccionamiento del contrato; casos en los cuales se atenta contra el mencionado principio que obliga a las partes a ejecutar el contrato de buena fe, esto es, que ambas partes deben cooperar dirigiendo su comportamiento a la realización de los intereses individuales de una y otra ${ }^{4}$.

Por otro lado, la buena fe exige a la parte fuerte respetar la confianza que el adherente ha depositado legítimamente en ella respecto al contenido justo o equilibrado del contrato que le será impuesto ${ }^{49}$; de manera que, en los eventos en que el predisponente inserta cláusulas abusivas en el contenido del contrato con el propósito de obtener ventajas adicionales, estaría defraudando la confianza que la parte débil ha depositado en él, situación que para nosotros constituye una violación al principio de la buena fe.

tractual por el predisponente; por su parte, el juez podrá declarar nula o ineficaz la cláusula abusiva o resuelto el contrato, si la relación contractual es notoriamente desequilibrada". Cfr. Cárdenas Mejía, Justicia y abuso contractual, cit., p. 707.

46 Roppo, El contrato del dos mil, cit., p. 59: "la cláusula es abusiva cuando el significativo desequilibrio de los derechos y de las obligaciones de las partes resulte contrario a la buena fe". Cfr. Camilo Andrés Rodríguez Yong, Una aproximación a las cláusulas abusivas, Bogotá, Legis, Universidad del Rosario, 2013, pp. 36 y 37 .

47 Ordoqui Castilla, Buena fe contractual, cit., p. 3 I 6: "como la buena fe permitió una contratación más despersonalizada, también fue lo suficientemente estricta en poner claros los límites de posibles abusos evitando que el contrato de adhesión se use como instrumento de explotación del fuerte sobre el débil".

48 Emilio Betтi, Teoría general de las obligaciones, trad. José Luis de los Mozos, Revista de Derecho Privado, Madrid, I969, p. Io2: "La buena fe de que se trata aquí, en cambio, es esencialmente una actitud de cooperación encaminada a cumplir de modo positivo la expectativa de la otra parte; actitud que tiene como aspectos más destacados la confianza, la fidelidad, el compromiso, la capacidad de sacrificio, la prontitud en ayudar a la otra parte y, en cuanto a los tratos preparatorios del contrato, la lealtad y veracidad hacia la otra parte contratante".

49 Juan Pablo Cárdenas Mejía, "La protección del contratante y la evolución del derecho contemporáneo", en Los contratos en el derecho privado, dirs. académicos Fabricio Mantilla Espinosa y Francisco Ternera Barrios, Bogotá, Colegio Mayor de Nuestra Señora del Rosario y Legis, 2007, p. 779: "cuando se crea una legítima expectativa [...], la misma debe respetarse y el texto mismo del contrato no puede ir en contra de ella. Además que no puede quedar una parte librada al arbitrio de la otra". 


\section{C. Ámbito de aplicación de la teoría de las cláusulas abusivas}

El ámbito de aplicación de la teoría de las cláusulas abusivas lo analizaremos desde dos perspectivas diferentes, una subjetiva y otra objetiva.

El ámbito subjetivo de la teoría de las cláusulas abusivas se refiere de manera general, al adherente, toda vez que al ser la parte débil dentro de la relación nacida de los contratos de adhesión, la ley le otorga una protección especial, con fundamento en el artículo i 3 de la Constitución Política de Colombia ${ }^{50}$, con el propósito de evitar un aprovechamiento indebido de la posición de superioridad en la que se encuentra el predisponente en el momento de fijar las reglas que regirán la relación contractual entre ellos ${ }^{5}$.

Ahora bien, no podemos olvidar que en derecho colombiano, si el adherente ostenta la calidad de consumidor, entonces quedará sometido al régimen de protección general establecido en la Ley i 480 de 20 I I (Estatuto del Consumidor); si el consumidor es adherente de un contrato de servicios públicos domiciliarios, estará protegido por el régimen especial previsto en la Ley I 42 de I994; y si es adherente de un contrato bancario o financiero, será protegido por el régimen especial previsto en la Ley I 328 de 2009.

En todo caso, también puede suceder que el adherente no ostente la calidad de consumidor, evento en el cual no quedará sometido a ningún régimen especial de protección de los mencionados anteriormente. Sin embargo, no quedará desprotegido, porque se le aplicarán las normas del derecho común, dentro de las cuales sobresale el artículo i624 C.C., de acuerdo con el cual "se interpretarán las cláusulas ambiguas a favor del deudor", y "las cláusulas ambiguas que hayan sido extendidas o dictadas por una de las partes, sea acreedora o deudora, se interpretarán contra ella, siempre que la ambigüedad provenga de la falta de una explicación que haya debido darse por ella". Adicionalmente, la jurisprudencia ${ }^{52}$ y la doctrina ${ }^{53}$ han extendido la aplicación de la teoría de las cláusulas abusivas

50 Constitución Política de Colombia, art. I3. Cfr. Posada Torres, El equilibrio contractual en los contratos de adhesión, cit., pp. 42-46.

5 I Rubén Stiglitz y Gabriel Stiglitz, Contratos, Parte general, dirs. Atilio Aníbal Alterini y Roberto M. López Cabana, Abeledo-Perrot, Buenos Aires, i 993, p. I36: "las cláusulas abusivas son tales porque desnaturalizan (alteran, desfiguran) el vínculo obligacional, la relación de equivalencia, lo que ineludiblemente presupone dos centros de interés y no sólo uno". Cfr. Corte Suprema de Justicia, Sala de Casación Civil, sentencia del 2 de febrero de 200I, exp. 5670, M.P.: Carlos Ignacio Jaramillo Jaramillo.

52 Laudo arbitral en derecho, I. ${ }^{\circ}$ de diciembre de 2006, Centro de Arbitraje y Conciliación de la Cámara de Comercio de Bogotá, árbitros: Carlos Esteban Jaramillo Scholls, Juan Pablo Cárdenas Mejía y Gabriel Jaime Arango Restrepo, demandante: Concelular S.A. (en liquidación), demandado: Comunicación Celular S.A., Comcel S.A.: "En principio, la doctrina de las cláusulas abusivas se ha aplicado a las relaciones contractuales con consumidores, pero en teoría nada se opone a que se dé la situación abusiva en contratos celebrados entre profesionales".

53 Aníbal Alterini, Treinta estudios de derecho privado, cit., p. 243: "las cláusulas abusivas [...] son naturalmente inaceptables para el derecho común, tanto en los contratos de empresa como 
a los contratos negociados, caso en el cual el juez deberá realizar un análisis de las circunstancias en que fue celebrado el contrato y de la manera como ha sido ejecutado para determinar si existe o no en su contenido una cláusula abusiva o vejatoria, y de existir, su sanción será la nulidad 54 .

En relación con el ámbito objetivo de aplicación de la teoría de las cláusulas abusivas se reconoce que el régimen de protección se brinda regularmente a los contratos de adhesión, aunque no podemos desconocer que en derecho colombiano su aplicación ha sido extendida por la doctrina a los contratos negociados, entendidos como aquellos en los cuales el contenido es discutido y fijado por las partes en un estado de igualdad jurídica55.

\section{Concepto y características generales de las cláusulas abusivas}

El artículo 42 de la Ley I 480 de 20 I I define las cláusulas abusivas como "aquellas que producen un desequilibrio injustificado en perjuicio del consumidor y las que, en las mismas condiciones, afecten el tiempo, modo o lugar en que el consumidor puede ejercer sus derechos".

En relación con esta definición legal consideramos pertinente realizar los siguientes comentarios: en primer lugar, circunscribe la existencia de las cláusulas abusivas únicamente a los contratos de adhesión en los cuales el adherente, como parte débil, ostenta la calidad de consumidor; en segundo lugar, entiende que son cláusulas abusivas las que generan un desequilibrio injustificado que vulnera los intereses del consumidor, así como las que impiden o entorpecen el ejercicio de los derechos del mismo. De esta manera observamos, por una parte, que la ley pretende que el contrato sea el instrumento a través del cual ambas partes (predisponente y adherente) satisfagan sus intereses individuales, proscribiendo cualquier posibilidad de que el contrato se convierta en el instru-

en cualquier contrato". Cfr. Posada Torres, El equilibrio contractual en los contratos de adhesión, cit., p. I 70.

54 Bianca, Derecho civil, 3, El contrato, cit., p. 388: "La ineficacia de las cláusulas abusivas que carecen de aprobación específica no se extiende a todo el contrato. En jurisprudencia la posibilidad de un juicio de nulidad total se admite en aplicación del principio sobre la nulidad parcial que hace nulo todo el contrato cuando se deduce que los contratantes no lo habrían celebrado sin aquella parte del contenido que está afectada de nulidad”. Cfr. Rodríguez Yong, Una aproximación a las cláusulas abusivas, cit., p. 67.

55 Larroumet, Teoría general del contrato, cit., p. 388: "el legislador ha pretendido establecer la eliminación de las cláusulas abusivas de manera general y no separadamente en determinado contrato [...]. Aunque el terreno preferido por las cláusulas abusivas sea el del contrato de adhesión, lo cierto es que eventualmente se pueden encontrar cláusulas abusivas en contratos que no son de adhesión. Sin embargo, en estos casos, debido a la libre negociación de las estipulaciones del contrato entre las partes, es muy difícil determinar cuándo llega a ser abusiva una cláusula”. Cfr. Rezzónico, Contratos con cláusulas predispuestas, condiciones negociales generales, cit., p. I 45 . 
mento de satisfacción exclusiva de los intereses del empresario predisponente ${ }^{56}$. Por otra parte, la ley persigue que el contrato de adhesión no se erija como un instrumento de subordinación, donde el adherente sea colocado en una posición de ulterior inferioridad que le impida el ejercicio de sus derechos, quedando a la merced del predisponente 57 ; precisamente, si el contrato es un mecanismo de armonización de los intereses individuales de las partes, ambas tienen que tener la posibilidad de ejercer eficientemente sus derechos para que se logre materializar el principio de igualdad jurídica que reconoce y pregona nuestro ordenamiento jurídico ${ }^{5}$.

De acuerdo con la jurisprudencia 59 y la doctrina ${ }^{60}$, las características generales de las cláusulas abusivas son las siguientes.

\section{Que la cláusula sea predispuesta}

La cláusula es predispuesta cuando es impuesta por el predisponente al adherente, sin posibilidad alguna de discutirla ni modificarla ${ }^{6}$. En otras palabras, se trata

56 Corte Suprema de Justicia, Sala de Casación Civil, sentencia del 8 de septiembre de 20 I I, ref. I IOO I-3 IO3-02 6-2000-043366-O I, M.P.: William Namén Vargas: "El contrato, antes que acto jurídico, responde a causas de contenido económico y social. Los particulares ejercen su autonomía privada para obtener la recíproca satisfacción de sus necesidades e intereses, y acuden al negocio jurídico con ese designio. Las partes de una estipulación se comprometen a una prestación, con el ánimo de cumplirla, so pena de responder por los perjuicios que pueda ocasionar su incumplimiento en la parte contraria; de manera que cada una de las partes de la relación negocial está autorizada para confiar en que su contraparte honrará los deberes asumidos".

57 Corte Constitucional, Sala Plena, sentencia C-I I 4 I de 2000, M.P.: Eduardo Cifuentes Muñoz: "La Constitución ordena la existencia de un campo de protección a favor del consumidor, inspirado en el propósito de restablecer su igualdad frente a los productores y distribuidores, dada la asimetría real en que se desenvuelve la persona que acude al mercado en pos de la satisfacción de sus necesidades humanas. [...]. [N]o puede entonces en modo alguno ignorarse la posición real del consumidor y del usuario, puesto que justamente su debilidad en el mercado ha sido la circunstancia tenida por el constituyente para ordenar su protección”.

58 Corte Constitucional, Sala Sexta de Revisión, sentencia T-5 I 7 de 2006, ref. Ti 308 I 2 5, M.P.: Marco Gerardo Monroy Cabra: "La libertad de contratación deriva de la Constitución una doble garantía: [...] garantizar relaciones justas y libres. Esto [...] debe hacerlo la ley cuando la autonomía privada se revele insuficiente para asegurarlas y dicha intervención venga exigida por el principio de solidaridad y la necesidad de imponer la igualdad sustancial, particularmente si la autonomía solo resulta predicable de algunos agentes económicos o sujetos y el poder privado llega a traducirse en abuso, daño o expoliación de la parte débil cuya libertad negocial pasa a ser puramente formal".

59 Corte Suprema de Justicia, Sala de Casación Civil, sentencia del 2 de febrero de 200 , exp. 5670, M.P.: Carlos Ignacio Jaramillo Jaramillo: “características arquetípicas de las cláusulas abusivas [...]: a) que su negociación no haya sido individual; b) que lesionen los requerimientos emergentes de la buena fe negocial -vale decir, que se quebrante este postulado rector desde una perspectiva objetiva: buena fe probidad o lealtad-, y c) que genere un desequilibrio significativo de cara a los derechos y obligaciones que contraen las partes".

6o Rodríguez Yong, Una aproximación a las cláusulas abusivas, cit., pp. 52-58.

6i González de Alaiza Cardona y Pertíñez Vílchez, Los contratos de adhesión y la contratación 
de una cláusula que no es negociada por las partes, sino que, por el contrario, es impuesta por el predisponente al adherente, como sucede normalmente en los contratos de adhesión.

Ahora bien, resulta importante preguntarse si todas las cláusulas que integran el contenido de los contratos de adhesión son predispuestas. Al respecto, un sector de la doctrina se decanta por la negativa, y ello por cuanto las puede haber que son negociadas o que transcriben normas legales imperativas, supuestos en los que se descarta su predisposición, y como consecuencia de ello, tales cláusulas quedarán excluidas del control de contenido de cláusulas abusivas. Así las cosas, las cláusulas que contienen prestaciones fundamentales o esenciales del contrato particular que celebran las partes no se entienden como predispuestas, porque normalmente sobre estas prestaciones existe negociación entre las partes ${ }^{62}$, no obstante lo cual podrán ser abusivas si el predisponente no cumple con la carga de claridad que le impone la ley ${ }^{6}$; como sucede con las cláusulas relacionadas con los productos que se venderán o los servicios que se prestarán, el precio de venta, los intereses, entre otras.

Por otro lado, en relación con las cláusulas que transcriben normas legales de carácter imperativo, se excluye la naturaleza predispuesta de las mismas porque se entiende que la imposición proviene del legislador y no del predisponente ${ }^{64}$. De esta manera, tendríamos que las cláusulas predispuestas son las que modifican elementos de la naturaleza o accidentales del contrato particular que celebran las partes ${ }^{65}$, que usualmente están consagradas en normas dispositivas respecto

electrónica, cit., p. I 592: "Lo relevante para que una cláusula sea considerada predispuesta no es que haya sido formulada por el predisponente o por un tercero, antes de la celebración del contrato, sino que la cláusula tuviera una existencia anterior al inicio mismo de la fase precontractual; es decir, la predisposición se identifica con la ausencia de negociación”.

62 Adela Serra Rodríguez, "Condiciones generales de la contratación y cláusulas abusivas celebrados con consumidores", en Derecho privado de consumo, coord. María José Reyes López, Valencia, Tirant lo Blanch, 2005, p. 358: "La doctrina mayoritaria (...) entiende excluidas del ámbito de control del art. Io. I LGDCu las cláusulas que regulan los elementos esenciales del contrato (prestación principal y precio), al no tratarse de verdaderas condiciones generales, ya que no vienen impuestas al adherente, sino que son libremente consentidas en virtud de la autonomía privada”. Cfr. Rezzónico, Contratos con cláusulas predispuestas, cit., pp. i I y i I .

63 Antonio Juan Rinessi, Relación de consumo y derechos del consumidor, Buenos Aires, Astrea de Alfredo y Ricardo Depalma, 2006, p. 220 : "La apreciación del carácter abusivo de las cláusulas no se referirá al objeto principal del contrato ni a la adecuación entre precio o retribución, por una parte, ni a los servicios o bienes que hayan de proporcionarse como contrapartida, por otra, siempre que dichas cláusulas se redacten de manera clara y comprensible".

64 Javier Pagador López, "Condiciones generales y cláusulas abusivas", en La defensa de los consumidores y usuarios, dirs. Manuel Rebollo Puig y Manuel Izquierdo Carrasco, Madrid, Iustel, 20 I I, p. I 342: "Por no reunir este elemento, no se consideran cláusulas de condiciones generales aquéllas que se limiten a reproducir una disposición de carácter general, imperativa o dispositiva, que sería en todo caso aplicable".

65 Rengifo García, Del abuso del derecho al abuso de la posición dominante, cit., p. 226 : "lo que hace la Directiva 93/I 3 es recoger la distinción, tradicional en la doctrina alemana, entre las llamadas 
de las cuales la ley permite al predisponente apartarse de ellas, esto es, del modelo propuesto por el legislador en desarrollo de su autonomía privada, con el fin de fijar las reglas a las que se someterán voluntariamente tanto él como el adherente para satisfacer sus respectivos intereses individuales.

\section{Que la cláusula genere un desequilibrio jurídico en el contrato}

El concepto de equilibrio contractual se encuentra estructurado sobre dos dimensiones: una económica y otra jurídica, en atención a las dos finalidades que cumple el contrato: como instrumento económico, que permite el intercambio $^{66}$, y como instrumento jurídico, a través del cual las partes fijan las reglas a las que se someterán voluntariamente para dirigir sus comportamientos hacia la satisfacción recíproca de sus intereses individuales ${ }^{67}$. Además de esto, cada una de las mencionadas dimensiones tiene señaladas en la ley unas causales que implican su ruptura, de manera que la ocurrencia de cualquiera de ellas conlleva el rompimiento del equilibrio del contrato en alguna de sus dimensiones, sin desconocer que podrían concurrir varias causales que alteren el equilibrio contractual en sus dos dimensiones, de tal manera que estas no son excluyentes sino complementarias entre sí.

A continuación analizaremos únicamente la dimensión jurídica del equilibrio contractual, que es la que más relevante para los propósitos de esta investigación.

El equilibrio jurídico del contrato consiste en que las partes, como consecuencia del perfeccionamiento del contrato, adquieran derechos y contraigan obligaciones recíprocas y equivalentes entre si $^{68}$. De ese modo, todas las cláu-

prestaciones principales o fundamentales $[\ldots]$ y los denominados pactos accesorios o pactos ordinarios [...], cuya consecuencia es clara: mientras que las primeras se excluyen del ámbito de aplicación de la norma de control de contenido, los segundos, que son los que se regulan típicamente mediante condiciones generales de la contratación, quedan plenamente inmersos en él”.

66 Messineo, Doctrina general del contrato, cit., p. 34: "El contrato, cualquiera que sea su figura concreta, ejerce una función y tiene un contenido constante: el de ser el centro de la vida de los negocios, el instrumento práctico que realiza las más variadas finalidades de la vida económica que impliquen la composición de intereses inicialmente opuestos, o por lo menos no coincidentes". Cfr. IÑIgo de la Maza Gazmuri, "Contratos por adhesión y cláusulas abusivas ¿Por qué el Estado y no solamente el mercado?", Revista Chilena de Derecho Privado n. ${ }^{\circ}$ I, 2003 , rog.

67 Emilio Betтi, Teoría general del negocio jurídico, trad. A. Martín Pérez, Granada, Comares, 2008, p. 57: "Es el acto con el cual el individuo regula por sí los intereses propios en las relaciones con otros [...], y al que el Derecho enlaza los efectos más conformes a la función económicosocial que caracteriza su tipo". Cfr. Luigi Cariota Ferrara, El negocio jurídico, trad. Manuel Albaladejo, Madrid, Aguilar, I956, pp. 43 y 44.

68 Roppo, El contrato de dos mil, cit., p. 48: "las normas señaladas tutelan no ya el equilibrio económico del contrato, sino sólo su equilibrio normativo, ese equilibrio de derechos y obligaciones contractuales $[\ldots]$ cuya ausencia, generadora del correspondiente desequilibrio, es lo que acerca el contrato a los remedios apenas vistos arriba". 
sulas dirigidas a mantener en estado de inferioridad al adherente, a impedirle o dificultarle el ejercicio de sus derechos, a reafirmar la posición de superioridad en la que se encuentra el predisponente, a aliviar o exonerar a este de responsabilidades, entre otras, conllevan el rompimiento del equilibrio contractual, porque ellas no permiten verificar la reciprocidad y equivalencia de derechos adquiridos y obligaciones contraídas que exige el ordenamiento jurídico en los contratos.

Tratándose de contratos de adhesión, es el predisponente quien elabora el contenido del contrato fijando unilateralmente las reglas a las que se someterá de manera voluntaria el adherente, sin que exista la mínima posibilidad para él de discutir ni modificar ninguna de las reglas así impuestas; situación esta que implica un mayor riesgo de existencia de cláusulas abusivas en sus contenidos, pues el predisponente, en ejercicio de su autonomía privada, puede incluir algunas cláusulas que lo beneficien de manera exorbitante sin importar que se torne más gravosa la posición del adherente ${ }^{69}$. Este riesgo se encuentra fundamentado en la desigualdad propia que existe entre las partes en los contratos de adhesión, a partir de la cual el predisponente aprovecha su posición de superioridad contractual para establecer reglas que privilegien su posición negocial respecto de la del adherente ${ }^{70}$. Sin embargo, el principio de la buena fe contractual exige al predisponente obrar con lealtad, corrección y honestidad, de manera que este debe obrar con objetividad en el momento de elaborar las reglas que impondrá al adherente, de modo de no privilegiar sus intereses individuales por encima de los intereses del adherente ni ir en detrimento de sus derechos; e igualmente exige que los derechos que ellos adquieran y las obligaciones que contraigan sean recíprocas y equivalentes entre sí; de esta manera el predisponente, como parte fuerte del contrato, podrá lograr la realización del deber ser, esto es, dar un trato igualitario al adherente, manifestado en el carácter justo del contenido predispuesto del contrato ${ }^{7 \mathrm{I}}$.

69 Juan M. Farina, Contratos comerciales modernos $I, 3 .{ }^{a}$ ed., Buenos Aires, Astrea de Alfredo y Ricardo Depalma, 2005, p. I90: "Mediante las cláusulas predispuestas, las condiciones generales del contrato y, por lo común, aprovechando su posición dominante en la contratación, las empresas procuran tener, frente a la parte contraria, posiciones jurídicas ventajosas de todo orden, para lo cual emplean cláusulas abusivas, en detrimento de los derechos del público consumidor".

70 Messineo, Doctrina general del contrato, cit., pp. 52 y 53: "Paridad jurídica significa que ambos contratantes gocen de tutela de igual intensidad por parte de la ley; que ninguno de ellos pueda apelar sino a la libre determinación del otro para que estipule el contrato (libertad de contratar) y que ninguno de ellos pueda imponer unilateralmente el contenido del contrato [...]: paridad económica significa que cada uno de los contratantes está en condición de no sufrir la presión psíquica del otro. De esta paridad no se preocupa por lo común el ordenamiento jurídico [...]. Sólo interviene la ley en situaciones particulares en las que el ignorar la disparidad económica y no remediarla en alivio del contratante económicamente débil daría lugar a consecuencias en pugna con la equidad y con la ética".

7 I Gustavo Ordoqui Castilla, Buena fe contractual, $2 .^{a}$ ed., Bogotá, Pontificia Universidad Javeriana, Universidad Católica del Uruguay y Grupo Editorial Ibáñez, 20 2, p. 3 Io: "el que impone el contrato por adhesión al preformular su contenido, debe actuar con honradez, 
Para que se pueda hablar de cláusulas abusivas, estas tienen que generar un desequilibrio jurídico en el contrato, entendido como una alteración que rompa el equilibrio que debe existir en relación con los derechos adquiridos, las obligaciones contraídas y las responsabilidades asumidas por las partes con ocasión del perfeccionamiento del contrato ${ }^{72}$. En consecuencia, no serán consideradas como cláusulas abusivas aquellas que alteren el equilibrio económico de las prestaciones del contrato, porque normalmente estas cláusulas son negociadas entre las partes ${ }^{73} \mathrm{y}$, adicionalmente, porque el ordenamiento jurídico prevé una serie de mecanismos dirigidos a recomponer el equilibrio económico del contrato $^{74}$. En todo caso, cuando una cláusula rompa el equilibrio contractual alterando tanto el equilibrio jurídico del mismo como el equilibrio económico de las prestaciones contractuales, estaremos frente a una cláusula abusiva en razón de la alteración del equilibrio jurídico del contenido contractual 75 .

\section{Que el desequilibrio sea injustificado}

Este requisito hace referencia a que no cualquier desequilibrio jurídico que sufra el contrato implica la existencia de cláusulas abusivas, pues para que esta se pueda predicar es necesario que se trate de un desequilibrio relevante que altere el equilibrio que debe existir entre los derechos adquiridos y las obligaciones

lealtad, equilibrio, claridad, $y$, por otra parte, el adherente, en cuanto se protege su buena fe subjetiva, confía en que el contrato que firma no es abusivo o desequilibrado".

72 Manuel Fernández Allende, Contratos por adbesión y cláusulas abusivas, ilegales o inequitativas, en Defensa de los consumidores de productos y servicios, daños-contratos, dir. Gabriel Stiglitz, La Rocca, Buenos Aires, I 994, p. 236 : "Respecto de las cláusulas abusivas, inequitativas o ilícitas, las mismas coinciden en la extremada ventaja de los derechos del proveedor en perjuicio del consumidor, o que puedan establecer estipulaciones inequitativas en merma de los derechos de los consumidores y aun renuncias a los mismos, y que consecuentemente colocan a los propios consumidores en situación económica perjudicial e inequitativa en la relación proveedorconsumidor".

73 Ricardo Luis Lorenzetti, "Tratamiento de las cláusulas abusivas en la ley de defensa del consumidor", Revista de Derecho Privado y Comunitario, n. ${ }_{5}$, Consumidores, Rubinzal-Culzoni, p. i 8 I: "el precio o la remuneración en tanto son ejercicio de una libertad no son abusivos".

74 Posada Torres, El equilibrio contractual en los contratos de adhesión, cit., p. I 73: "los mecanismos jurídicos dirigidos a la preservación o al restablecimiento del equilibrio económico de las prestaciones al momento de su celebración (equilibrio económico u originario), donde encontramos principalmente los vicios del consentimiento, la lesión y las normas de protección de la libre competencia; y con relación al equilibrio económico de las prestaciones durante la ejecución del contrato (equilibrio sobrevenido), [...] la teoría de la imprevisión, la excesiva onerosidad, la base del negocio jurídico y la intervención del Estado en la fijación de precios”.

75 Rodríguez Yong, Una aproximación a las cláusulas abusivas, cit., p. 53: “para considerar abusiva una cláusula, se requiere siempre un desequilibrio normativo, sin importar que al mismo tiempo ocurra uno de carácter económico y viceversa; no se estará en presencia de una cláusula abusiva si a pesar de estar en presencia de un desequilibrio económico, no se demuestra la existencia de uno normativo". 
contraídas por las partes como consecuencia de la celebración y perfeccionamiento del contrato ${ }^{7}$. De esta manera, se ha considerado que, en todos los casos en que no existe ninguna razón legítima que le permita al predisponente justificar la inclusión de alguna o algunas cláusulas que implican una alteración del equilibrio jurídico del contrato, apartándose de las normas dispositivas que establecían un contenido equilibrado ${ }^{77}$, se presenta un desequilibrio relevante del mismo.

Para establecer en qué eventos el desequilibrio jurídico producido por una cláusula es injustificado, el ordenamiento jurídico impone que para decidir sobre su eventual abusividad deberá realizarse la valoración de las circunstancias que estuvieron presentes al momento de adoptarse una determinada cláusula; valoración que se adelantará a partir de la existencia o no de una razón legítima que permita justificar el desequilibrio jurídico del contrato causado por el apartamiento del predisponente del derecho dispositivo ${ }^{78}$. Sin embargo, no podemos desconocer que la Ley I480 de 20 i I, a través de la lista negra79 consagrada en su artículo 43, enumera de manera taxativa las cláusulas que el legislador considera que, sin importar las circunstancias en que sean incorporadas al contenido del contrato de adhesión, implican un desequilibrio relevante e injustificado, y por ende les impone como sanción la ineficacia de pleno derecho, para proteger de manera eficaz los derechos de los consumidores como contratantes débiles que son.

\section{Que la cláusula sea contraria al principio de la buena fe}

El principio de la buena fe contractual no solo impone a las partes tener conciencia e intención de obrar correctamente durante todas las etapas del iter contractus, sino, adicionalmente, el deber de actuar con lealtad, confianza, honestidad y transparencia en todas ellas para asegurar la satisfacción tanto de sus propios intereses individuales como de los del otro contratante.

76 Rengifo García, Del abuso del derecho al abuso de la posición dominante, cit., p. I93: "habrá de reputarse abusivas, y por tanto nulas, aquellas cláusulas predispuestas que, pese a las exigencias de la buena fe, causen en detrimento del consumidor o adherente un desequilibrio significativo o importante entre los derechos y las obligaciones que se derivan del contrato".

77 Ordoqui Castilla, Abuso del derecho, cit., p. I 8 I : "debe ser injustificado, o sea, que la diferencia en la distribución de derechos y obligaciones carezca de razón o de causa o de contrapartida. El desequilibrio está justificado si es propio del alea del contrato de que se trata". Cfr. DíezPicazo, Fundamentos del derecho civil patrimonial, cit., p. 379.

78 González de Alaiza Cardona y Pertíñez Vílchez, Los contratos de adhesión y la contratación electrónica, cit., p. I645: "algunos de los supuestos en ella contemplados no se pueden aplicar automáticamente sin una previa valoración de las circunstancias concurrentes en el contrato concreto, de la naturaleza del bien o servicio objeto del contrato y de otros pactos o estipulaciones del contrato".

79 Soто. La transformación del contrato: del contrato negociado al contrato predispuesto, cit., p. 423. Cfr. Posada Torres, El equilibrio contractual en los contratos de adhesión, cit., pp. I94 y i 95. 
La doctrina y la jurisprudencia han dado proporcionado argumentos para afirmar que las cláusulas abusivas son contrarias al principio de la buena fe, entre los cuales los más relevantes son los siguientes: en primer lugar, se considera que el principio de la buena fe contractual impone a los contratantes un deber de cooperación, de acuerdo con el cual el predisponente debe colaborar con la satisfacción de los intereses individuales del adherente ${ }^{80}$. Así las cosas, en los eventos en que el predisponente incluye cláusulas abusivas en el contenido del contrato, alterando con ello su equilibrio jurídico, se asume que no está contribuyendo a la satisfacción de los intereses individuales del adherente, toda vez que, de manera general, las cláusulas abusivas están orientadas a desconocer derechos del adherente o a trabar su ejercicio, para obtener beneficios que privilegian la satisfacción de los intereses individuales del predisponente por encima de los del adherente; de esta forma, la inobservancia del deber de cooperación por parte del predisponente conlleva la violación del principio de la buena fe.

$\mathrm{Y}$, en segundo lugar, se ha establecido que el principio de la buena fe contractual impone al predisponente honrar la confianza que el adherente ha depositado en él, con respecto a la elaboración de un contenido contractual justo $^{8 \mathrm{I}}$, que no le impida ejercer sus derechos, que no le imponga de manera desmedida obligaciones que lo mantengan en una posición de inferioridad y que le permita satisfacer eficientemente sus intereses individuales. Entonces, cuando el predisponente inserta cláusulas abusivas en el contenido predispuesto del contrato de adhesión defrauda la confianza del adherente, consolidándose así la contrariedad con la buena fe.

Ahora bien, consideramos que los argumentos antes explicados son válidos y complementarios entre sí porque cada uno de ellos resalta una de las múltiples manifestaciones del principio de la buena fe contractual que vislumbran su complejidad. Lo que sí es cierto es que las cláusulas abusivas insertadas en los contenidos contractuales predispuestos contrarían el principio de la buena fe, ya sea porque van en contra del deber de cooperación o porque defraudan la confianza depositada por el adherente en un contrato justo.

80 CÁrdenas Mejía, fusticia y abuso contractual, cit., p. 706: "cada contratante debe observar una conducta leal, lo que se traduce en una actitud de cooperación encaminada a cumplir de modo positivo la expectativa de la otra parte y, en particular, a hacer todo cuanto sea necesario para asegurar a la otra parte el resultado útil de la prestación".

8i González de Alaiza Cardona y Pertíñez Vílchez, Los contratos de adhesión y la contratación electrónica, cit., p. I632: "El juicio de buena fe se refiere a la valoración de la adecuación de la conducta del predisponente a un parámetro objetivo de lealtad y honestidad, en un momento histórico concreto, el de la predisposición. La conducta exigida al predisponente, conforme a la buena fe, viene dada por el respeto a la confianza del consumidor en la honestidad del tráfico jurídico. El consumidor puede confiar en que un predisponente que se comporta conforme a la buena fe, no introducirá mediante las cláusulas predispuestas una reglamentación contractual que no tenga en cuenta sus intereses, ni un contenido contractual que se aparte del equilibrio económico pactado, o que frustre sus expectativas legítimas sobre el contrato". 


\section{Tipología de cláusulas abusivas}

En esta parte de la investigación analizaremos puntualmente algunas cláusulas abusivas (las más polémicas), desde la perspectiva del régimen especial de protección establecido para los contratos de adhesión con consumidores, incorporado en la Ley I 480 de 20 I I, confrontando este régimen con el de protección general previsto para los contratos de adhesión entre empresarios (o no consumidores), cuando a ello haya lugar, con el propósito de determinar las razones que fundamentan la aludida abusividad.

\section{A. Cláusulas que limitan o exoneran la responsabilidad del predisponente}

Las cláusulas de limitación y exoneración de responsabilidad, también llamadas cláusulas de irresponsabilidad, están dirigidas a evitar o mitigar las consecuencias jurídicas previstas por el ordenamiento jurídico para los eventos en que el predisponente incumpla las obligaciones a su cargo previstas en la ley y en el contrato $^{82}$. Generalmente, estas cláusulas pueden estar dirigidas a excluir por completo la responsabilidad de una de las partes o a limitar su responsabilidad a determinados comportamientos o a una cuantía indemnizatoria específica ${ }^{83}$.

En tratándose de los contratos de adhesión entre empresarios (o no consumidores), son de tener en cuenta los artículos I $604^{[84]}$ y I 6 I $6^{[85]}$ C.C., de acuerdo

82 Rezzónico, Contratos con cláusulas predispuestas, cit., p. 496: "en la cláusula de irresponsabilidad, el deudor de una prestación se exonera de reparar los daños que una ejecución imperfecta o una inejecución pudiera causar a la persona, a los bienes o a los intereses patrimoniales de su cocontratante, siendo precisamente la CNG la sede más frecuente de éste tipo de cláusulas".

83 Juan M. Farina. Defensa del consumidor y del usuario, $3 \cdot{ }^{a}$ ed., Buenos Aires, Astrea de Alfredo y Ricardo Depalma, 2004, pp. 392 y 393: "cláusulas que pretenden limitaciones absolutas de responsabilidad frente al consumidor o usuario. [...] cláusulas que establecen limitaciones referidas a la utilidad o finalidad esencial del producto".

84 Código Civil colombiano, art. I604: "El deudor no es responsable sino de la culpa lata en los contratos que por su naturaleza solo son útiles al acreedor; es responsable de la leve en los contratos que se hacen para beneficio recíproco de las partes; y de la levísima en los contratos en que el deudor es el único que reporta beneficio.

"El deudor no es responsable del caso fortuito, a menos que se haya constituido en mora (siendo el caso fortuito de aquellos que no hubieran dañado a la cosa debida, si hubiese sido entrega al acreedor), o que el caso fortuito haya sobrevenido por su culpa.

La prueba de la diligencia o cuidado incumbe al que ha debido emplearlo; la prueba del caso fortuito al que lo alega.

"Todo lo cual, sin embargo, se entiende sin perjuicio de las disposiciones especiales de las leyes, y de las estipulaciones expresas de las partes".

85 Código Civil colombiano, art. I6 I6: "Si no se puede imputar dolo al deudor, sólo es responsable de los perjuicios que se previeron o pudieron preverse al tiempo del contrato; pero si hay dolo, es responsable de todos los perjuicios que fueron consecuencia inmediata o directa de no haberse cumplido la obligación o de haberse demorado su cumplimiento. 
con los cuales el ordenamiento jurídico permite a las partes, en desarrollo de su autonomía privada, pactar cláusulas que modifiquen su responsabilidad respecto de las obligaciones contraídas en los contratos que celebren. Esta facultad no es absoluta, sino que, por el contrario, se encuentra limitada por normas imperativas, por el orden público, por el principio de la buena fe, y por la moral y las buenas costumbres ${ }^{86}$. Así las cosas, para el derecho común, las cláusulas de irresponsabilidad que están absolutamente prohibidas son las que implican una condonación o renuncia del dolo futuro, y ello por cuanto desnaturalizan el concepto de obligación ${ }^{87}$.

Por otro lado, en los contratos de adhesión celebrados con consumidores el legislador, a través de normas imperativas, excluye toda posibilidad de incluir en los contenidos predispuestos cláusulas que exoneren o limiten la responsabilidad del predisponente respecto de las obligaciones que le impone la ley en relación con la calidad, idoneidad y seguridad de los productos que ofrece en el mercado $^{88}$. La razón de esta prohibición se encuentra en que dichas cláusulas entrañan de suyo un desequilibrio jurídico del contrato injusto e injustificado, que impide al consumidor ejercer el derecho a obtener una indemnización que repare los perjuicios sufridos como consecuencia del incumplimiento de alguna de las mencionadas obligaciones que la ley y/o el contrato le imponen, colocándolo en una situación de desigualdad e inferioridad mayor a aquella prevista y permitida por el legislador para este tipo de contratación; y adicionalmente, dichas cláusulas son contrarias al orden público, toda vez que asignan un riesgo mayor para el consumidor en la satisfacción de sus necesidades, desbordando el riesgo normal que asumen, ya que cualquier defecto o vicio que afecte el debido funcionamiento del producto adquirido, así como cualquier daño que sufra en su patrimonio o en su integridad física el consumidor, será asumido

"La mora producida por fuerza mayor o caso fortuito, no da lugar a indemnización de perjuicios.

"Las estipulaciones de los contratantes podrán modificar estas reglas".

86 Indira Díaz Lindao, "Límites a las cláusulas modificativas de la responsabilidad en el derecho moderno de los contratos", Revista de Derecho Privado, n. ${ }^{\circ} 23$, julio-diciembre de 2012 , Universidad Externado de Colombia, p. I40: "Se trata de disposiciones que ponen en evidencia el carácter dispositivo que en principio tienen las reglas que regulan el régimen de responsabilidad contractual, y por ende dejan presente la libertad que tienen las partes para modificarlas. Facultad que puede ser ejercida tanto para agravar como para atenuar dicho régimen. Empero, dicha libertad nunca ha sido absoluta, por el contrario, siempre ha estado sometida a los límites generales de la autonomía contractual, especialmente el orden público, las buenas costumbres y la buena fe, las cuales sin embargo han alcanzado un grado de especialidad de esta materia".

87 Código Civil colombiano, art. I 522 : "El pacto de no pedir más en razón de una cuenta probada, no vale en cuanto al dolo contenido en ella, si no se ha condonado expresamente. La condonación del dolo futuro no vale". Cfr. Hinestrosa, Tratado de las obligaciones I, cit., 263 y 265. Arturo Alessandri, Manuel Somarriva y Antonio Vodanovic, Tratado de derecho civil, partes preliminar y general, t. II, Santiago, Jurídica de Chile, I998, pp. 24I, 275 y 276.

Ley I 480 de 20 I , art. 20. Cfr. Constitución Política de Colombia, art. 78. 
única y exclusivamente por este; además de todo ello, también son contrarias al principio de la buena fe, en razón a que defraudan la confianza depositada por el consumidor en el carácter justo del contenido que se le impone ${ }^{89}$.

Por su parte, el Estatuto del Consumidor reconoce como uno de los derechos del consumidor que sea resarcido por los perjuicios que sufra como consecuencia de la adquisición y uso de productos que no tienen la calidad ofrecida, o que no funcionan adecuadamente para el propósito para el cual fueron adquiridos, o por los daños que aquel haya padecido en su patrimonio o en su integridad física ${ }^{\circ}$; adi- $^{-}$ cionalmente dispone que, por tratarse de normas imperativas, no se admite ningún pacto en contrario que excluya o restrinja la responsabilidad del predisponente.

En todo caso, no se puede desconocer que, en el artículo I 33 de la Ley I 42 de I994, el legislador no establece la abusividad per se de las cláusulas de irresponsabilidad, sino que, simplemente, dispone que se entenderán como abusivas cuando no sea posible para el predisponente desvirtuar la presunción de abusividad que sobre ellas pesa en la forma como lo establece la misma norma legal ${ }^{91}$; es decir, cuando sean contrarias al principio de la buena fe, ya sea porque no se informaron oportunamente al adherente, o porque colocan al predisponente en un estado de superioridad y privilegio, en detrimento de la satisfacción de los derechos e intereses individuales del adherente $\mathrm{e}^{9^{2}}$.

\section{B. Cláusulas que implican la renuncia de los derechos del adherente que le corresponden por ley}

De acuerdo con el artículo I 5 C.C., "podrán renunciarse los derechos conferidos por las leyes, con tal que sólo miren al interés individual del renunciante, y que

89 Ordoqui Castilla, Abuso del derecho, cit., p. 248: "Se recurre al principio de la buena fe; al de equivalencia de las prestaciones, la moral y las buenas costumbres como forma de evitar la vigencia de las cláusulas limitativas de responsabilidad en ciertas circunstancias, no obstante no existir dolo".

90 Giraldo López, Caycedo Espinel y Madriñán Rivera, Comentarios al nuevo Estatuto del Consumidor, Ley 1480 de 201 I , cit., p. 68: "en el esquema nacional el productor y el expendedor son solidariamente responsables de los daños causados por los defectos de sus productos [...]. Esta solidaridad simplifica para los consumidores el trámite de acciones para la reparación de la indemnización, pues el o los demandados no podrán oponer excepciones relativas a la titularidad de la responsabilidad, pues las controversias por atribución o repetición no serán parte del proceso adelantado por el consumidor".

9I Rinessi, Relación de consumo y derechos del consumidor, cit., p. 237: "El tema debe manejarse en concreto, lo que implica hacer una valoración de la cláusula o conjunto de cláusulas, para descubrir de esta manera si ellas implican o no violar el precepto legal”.

92 Serra Rodríguez, Condiciones generales de la contratación y cláusulas abusivas celebrados con consumidores, cit., pp. 326 y 337: "La finalidad de este control es asegurar que el adherente tenga un conocimiento de las condiciones generales, garantizando con ello que emite un consentimiento no viciado, una decisión libre y consciente. [...] [L]os parámetros que han de utilizarse para valorar el carácter abusivo de una cláusula: la buena fe y el justo equilibrio entre los derechos y obligaciones de las partes". 
no esté prohibida la renuncia”. Esta regla reconoce a los particulares la facultad de renunciar a los derechos que poseen cuando la ley no prohíba expresamente su renuncia, o bien cuando se trate de derechos que miren al interés general, porque en tal caso se tornan irrenunciables ${ }^{93}$.

En relación con los contratos de adhesión entre empresarios (o no consumidores), la abusividad de una cláusula siempre será decidida por el juez previa valoración de las pruebas aportadas oportunamente por las partes, relacionadas con las circunstancias particulares presentes al momento de la celebración del contrato 94 . Así las cosas, la Corte Suprema de Justicia fijó el alcance del artículo I95० C.C. sobre la irrenunciabilidad de la acción rescisoria por lesión enorme, y consideró que la cláusula que disponga la renuncia a ella será abusiva cuando sea pactada en el momento de la celebración del contrato, al igual que lo serán las cláusulas por medio de las cuales se dona el exceso del precio al predisponente, siendo válido y eficaz únicamente el pacto de su renuncia que realicen las partes con posterioridad a la celebración del contrato 95 .

Por otra parte, en relación con los contratos de adhesión con consumidores, el artículo 43 de la Ley i 480 de 20 i i prohíbe expresamente la inclusión de cláusulas que conlleven o impliquen la renuncia de cualquiera de los derechos del consumidor ${ }^{6}$, porque son abusivas por sí mismas; de esta manera, no admiten prueba en contrario que permita realizar una ponderación posterior de su abusividad, toda vez que el legislador hizo dicha ponderación previamente a la promulgación de la ley.

Ahora bien, en relación con los servicios públicos domiciliarios, el legislador consideró, con la promulgación de la Ley I42 de I994, que las cláusulas de renuncia de derechos de los consumidores no son abusivas por sí mismas, sino que se presume su abusividad, permitiéndole al predisponente probar la exis-

93 Fernando Hinestrosa, Tratado de las obligaciones i, 2. a ed., Bogotá, Universidad Externado de Colombia, 2003, p. 393: "Dentro del poder dispositivo del particular se encuentra su aptitud para despojarse de los derechos que posee, no simplemente para transmitirlos a otro sujeto, sino también para hacer dejación de ellos sin destinatario alguno. Entonces no se presenta transmisión, sino simplemente extinción, así esos derechos resulten adquiridos inmediatamente por otro individuo o vayan a beneficiarlo robusteciendo su posición”.

94 Corte Suprema de Justicia, Sala de Casación Civil, sentencia del i 9 de octubre de 20 I I, exp. 200 I-00847, M.P.: William Namén Vargas.

95 Corte Suprema de Justicia, Sala de Casación Civil, sentencia del i 9 de diciembre de 2005, exp. I 996- I02 74, M.P.: César Julio Valencia Copete: "se muestran claras estas últimas expresiones de la norma, pues de ellas se deduce que las manifestaciones del contratante perjudicado consignadas en el negocio mismo, dirigidas a impedir el ejercicio de la rescisión, incluida la del vendedor de donar el exceso, son cláusulas inválidas, que deben tenerse por no escritas, esto es, itérase, estipulaciones de la convención que no pueden surtir efectos. [...]. Prohíbe igualmente el artículo estipular donación del exceso, porque ello equivale a renunciar a la acción; pero, así como la renuncia de esta puede hacerse después, no hay óbice para que posteriormente se done el exceso, desde luego con sujeción a las reglas de las donaciones".

96 Ley I480 de 20 I I, art. 3 , num. I. 
tencia de una justificación apta para desvirtuar dicha presunción, en la forma como lo establece la misma ley, para que sea ponderada por el juez junto con las circunstancias en que fue celebrado dicho contrato 97 . De tal manera que, si el predisponente no logra desvirtuar la presunción sobre la cláusula, esta será reputada como abusiva y se le impondrá la sanción prevista por la ley.

\section{Cláusulas que trasladan al adherente o a un tercero que no sea parte en el contrato la responsabilidad del predisponente}

Por medio de estas cláusulas el predisponente pretende exonerarse total o parcialmente de responsabilidad, trasladando la responsabilidad al adherente o a un tercero que no es parte en el contrato de adhesión respectivo.

En relación con los contratos de adhesión con consumidores, estas cláusulas son abusivas por sí mismas porque el legislador, mediante normas imperativas, fijó un modelo de responsabilidad solidaria a los predisponentes (importador, fabricante y distribuidores o expendedores) con el fin de proteger los intereses del consumidor; de esta manera, la abusividad de estas cláusulas está arraigada en el hecho de que con ella el predisponente pretende trasladar la responsabilidad al consumidor o a un tercero respecto de la calidad, idoneidad o seguridad del producto adquirido; además de que atribuir una responsabilidad excesiva al consumidor implica un desconocimiento de dichas normas imperativas ${ }^{9}$.

La censura proviene del hecho de que normalmente, las cláusulas que trasladan la responsabilidad del predisponente a un tercero que no ha sido parte en el contrato tienen como propósito desestimular al consumidor a ejercer coactivamente el cumplimiento de sus derechos a través del aparato judicial, colocándolo en una situación de mayor indefensión que perjudica la satisfacción de sus intereses individuales y de sus derechos.

97 Farina, Defensa del consumidor y del usuario, cit., p. 398: "la sola renuncia no es per se causa de ineficacia, pues en determinadas circunstancias puede resultar justificada. [...] [T]iene por finalidad evitar que se le puedan imponer renuncias que impidan su acceso al bien o servicio, o que afecten aspectos no patrimoniales (integridad física, salud, honor) o que desequilibren la justicia conmutativa del contrato".

98 Corte Constitucional, Sala Plena, sentencia C- I I 42 del 30 de agosto de 2000, M.P.: Eduardo Cifuentes Muñoz: "Los defectos de los productos y servicios no son indiferentes para el consumidor y el usuario, pues las lesiones que generan pueden afectar su vida, su integridad física y su salud. De ahí que el derecho del consumidor reconozca como elemento de su esencia el derecho a obtener de los productores y distribuidores profesionales, el resarcimiento de los daños causados por los defectos de los productos o servicios, con el fin de garantizar su uso seguro (...). La supresión de la responsabilidad del productor, a la luz del texto constitucional, es absolutamente insostenible. [...] [E]llo significaría sacrificar bienes jurídicos tan preciosos como la vida, la seguridad de las personas. [...] [L]a ausencia de un régimen de responsabilidad del productor, altera y falsea la libre y sana competencia económica y afecta gravemente los parámetros éticos que sirven de marco a la libre circulación de mercancías”. 


\section{Cláusulas que establecen que el predisponente no reintegrará el precio recibido en caso de ejecución total o parcial del objeto del contrato}

En los contratos de adhesión entre empresarios (no consumidores), el adherente tiene derecho a que le reintegren total o parcialmente el precio que pagó por la adquisición de un bien o para la prestación de un servicio que no le fue entregado o que no le fue prestado debidamente, como consecuencia del ejercicio de la acción de resolución del contrato por incumplimiento del predisponente; y en efecto, deberá procederse a las restituciones mutuas, dentro de las cuales se encuentra la restitución del precio que pagó por dicho bien o servicio99.

En tratándose de contratos de adhesión con consumidores, el artículo 47 de la Ley I 480 de 20 I r regula el derecho de retracto para las ventas a distancia, las realizadas por medios no tradicionales y en los contratos de tiempo compartido. En los dos primeros eventos, el ejercicio del derecho de retracto por parte del consumidor implica que el contrato se resuelve y el predisponente deberá restituir al consumidor el precio total que este haya pagado al predisponente ${ }^{\text {IOO }}$. De manera que, si el predisponente retiene total o parcialmente el precio que le ha sido pagado con fundamento en una cláusula que lo faculte para ello, esta será abusiva, y por ende, ineficaz de pleno derecho.

Excepcionalmente, en un solo caso la Ley I 480 de 20 i i permite al predisponente retener una parte del precio que le ha sido pagado, cuando el consumidor ejerce el derecho de retracto. Nos referimos de manera específica a los contratos de tiempo compartido, para los cuales el artículo 47 ha previsto que el derecho de retracto deberá ser ejercido dentro de los treinta días calendario siguientes a la fecha de suscripción del respectivo contrato, de manera que si el consumidor lo ejerce dentro de los primeros cinco días calendario, el predisponente tendrá que devolver la totalidad del precio que le haya sido pagado, sin que pueda descontar ningún valor por ningún concepto; en cambio, cuando el consumidor ejerce el derecho de retracto entre el día seis y el día treinta del plazo, la ley le permite al predisponente descontar hasta un cinco por ciento del precio para

99 Guillermo Ospina Fernández y Eduardo Ospina Acosta, Teoría general del contrato y del negocio jurídico, 7. ${ }^{a}$ ed., Bogotá, Temis, 2005, pp. 540-550. Cfr. Código Civil colombiano, arts. I 546 y I 932 .

ioo José Ovalle Favela, "Los derechos de los consumidores", Revista de Derecho Privado, año Iv, n. ${ }^{\circ}$ I 2, septiembre-diciembre de 2005, Universidad Nacional Autónoma de México, p. 97: "Los contratos celebrados fuera del local comercial o en forma indirecta o mediata sólo se perfeccionan a los cinco días hábiles contados a partir de la entrega del bien o de la firma del contrato, lo primero que suceda. Durante ese lapso, el consumidor tiene la facultad de revocar su consentimiento sin responsabilidad alguna. La revocación debe hacerse mediante aviso o mediante la entrega del bien en forma personal, por correo registrado o por otro medio fehaciente. La revocación deja sin efecto el contrato, por lo que el proveedor deberá reintegrar el precio pagado. Los costos de flete y seguro corren a cargo del consumidor". 
sufragar los gastos que haya efectuado con ocasión de la celebración de dicho contrato, caso en el cual la cláusula no sería abusiva, sino eficaz ${ }^{\mathrm{IOI}}$.

\section{E. Cláusulas que imponen el pago de intereses no autorizados legalmente}

Las cláusulas de pago de intereses son propias de los contratos de mutuo de dinero con interés, de los contratos bancarios y de los contratos de compraventa a plazo. De esta manera, la ley establece el régimen al que se encuentran sometidos los intereses remuneratorios y moratorios, fijando el tope máximo de los intereses que pueden ser pactados y cobrados; así mismo, el ordenamiento jurídico asigna a la junta directiva del Banco de la República la función de fijar periódicamente la tasa de los intereses y la usura ${ }^{102}$, de manera que la autonomía privada del predisponente es reducida, porque solamente podrá fijar una tasa de interés inferior o igual a la establecida por la ley, pero en ningún caso podrá establecer tasas de interés que excedan el tope máximo de la usura.

En derecho colombiano se tienen normas jurídicas civiles y mercantiles que regulan los intereses remuneratorios y moratorios. Siguiendo a Jorge Cubides САмасно ${ }^{103}$, las reglas aplicables al interés remuneratorio son las siguientes: en materia civil, i) Si las partes no pactan intereses remuneratorios, el acreedor no los podrá cobrar, aunque si el deudor los paga no podrán repetirse (art. 2224 incisos I y 3 y art. 2233 C.C.); ii) Cuando las partes pactan el interés pero no fijan su tasa, entonces se entenderá que corresponde a la del interés legal que es del seis por ciento (art. 2232 C.C.); y iii) Si las partes pactan el interés y fijan su tasa, esta no podrá exceder en más de una mitad al interés corriente (art. 223 I C.C.). Y, en asuntos mercantiles: i) Si no se pacta el interés de plazo se presume que corresponde al interés legal que, en materia mercantil, corresponde al interés bancario corriente (arts. 884,885 y I I 63 C.Co.); ii) Si las partes pactan el interés pero no fijan su tasa, se entenderá que esta corresponde a la del interés

io i Giraldo López, Caycedo Espinel y Ramón Madriñán Rivera, Comentarios al nuevo estatuto del consumidor, Ley 1480 de 20 I I, cit., pp. I 3 I y I 32 : "b) Contratos de tiempos compartidos. En este tipo de ventas [...] existe un régimen especial, en que el término de retracto es de 30 días calendario a partir de la suscripción del contrato. [...] [S]i el retracto se realiza dentro de los cinco (5) primeros días de adquirido, el consumidor tendrá derecho a que se le devuelvan todas las sumas pagadas, mientras que si el retracto se ejercita entre el día $6 .^{\circ}$ y el día 30 , el operador podrá descontar, por concepto de gastos efectuados por razón de la venta, un porcentaje que no supere el $5 \%$ del valor recibido como cuota inicial del contrato de tiempo compartido".

io2 Cfr. Sergio Rodríguez Azuero, Contratos bancarios, su significación en América Latina, 2. reimpr. de la 6. ${ }^{a}$ ed., Bogotá, Legis, 2013, p. I 24. Cfr. Néstor Humberto Martínez Neira, Cátedra de derecho bancario colombiano, 2. ${ }^{2}$ ed., Bogotá, Legis, 2004, pp. I49-I67. Constitución Política de Colombia de i99 I, art. 372. Ley 3 I de r992, art. i6 literal e).

io3 Jorge Cubides Camacho, Obligaciones, 5. ${ }^{a}$ ed., Bogotá, Pontificia Universidad Javeriana, 2005 , pp. г6 г у г62. 
legal que, en materia comercial, corresponde al interés bancario corriente; y iii) Si las partes pactan el interés y fijan su tasa, esta no podrá exceder de una mitad del interés bancario corriente. Por otra parte, en relación con los intereses moratorios, si las partes no pactan el interés remuneratorio o lo pactan pero no fijan su tasa, deben tenerse en cuenta las siguientes reglas: i) Si las partes convinieron la tasa del interés remuneratorio, esta misma tasa será la de los intereses moratorios; ii) La tasa del interés corriente para los casos en que la ley expresamente lo autoriza ${ }^{\mathrm{I0}}$; y iii) En los eventos en que las partes no hayan pactado la tasa del interés remuneratorio y en los que la ley no autoriza expresamente la tasa del interés corriente, entonces será del seis por ciento (art. I6 I 7, inc. I C.C.). En todo caso, cuando las partes pactan el interés y fijan la tasa, en ningún evento podrá exceder de una mitad por encima del interés corriente (art. 223 I C.C.). Y, en materia comercial, cuando no se pacta el interés moratorio o no se establece su tasa, se entenderá que esta corresponde a la del interés bancario corriente aumentado en una mitad (art. 884 C.Co.); y, si las partes fijan el interés moratorio y determinan su tasa, esta no podrá ser superior a la tasa del interés bancario corriente (interés legal) aumentado en una mitad.

Ahora, bien, después de recordar las reglas que rigen en materia de intereses en derecho colombiano, y que determinan la validez y eficacia de las cláusulas sobre intereses, es el caso de responder a la pregunta: ¿son abusivas las cláusulas que imponen el pago de intereses no autorizados por la ley, insertadas en contratos de adhesión con consumidores y entre empresarios? La respuesta es que no son abusivas porque las cláusulas que fijan intereses remuneratorios y moratorios que exceden los topes máximos establecidos por la ley mercantil no estarían sometidas al control de contenido que impone la teoría de las cláusulas abusivas, toda vez que, al tratarse de prestaciones esenciales en los contratos de mutuo con interés, en los contratos bancarios y en las compraventas a plazo, son consideradas como negociadas, quedando sometidas a otros controles previstos por nuestro ordenamiento jurídico, como sería la pérdida de todos los intereses cobrados en exceso, aumentados en una suma igual, además de las sanciones penales previstas en la ley ${ }^{105}$. Sin embargo, en tratándose de contratos de adhesión con consumidores, las cláusulas sobre intereses podrán ser abusivas cuando el predisponente no cumple con la carga de claridad que le impone la Ley I480 de 20 I I $^{\left[{ }^{[06}\right]}$, es decir, cuando no son redactadas en lenguaje claro que

io4 Jaime Alberto Arrubla Paucar, Contratos mercantiles, teoría general del negocio mercantil, reimpr. de la I3. ${ }^{\text {a }}$ ed., Bogotá, Legis, 20 I3, p. 2 I6: "como por ejemplo: en la mora de las obligaciones de dinero (art. I6 7 C.C.), en las indemnizaciones del lucro cesante (art. I6 63 C.C.), en las prestaciones mutuas (arts. 964 y I 746 C.C.)".

io5 Hinestrosa, Tratado de las obligaciones I, cit., i 92-i 94. Cfr. Enrique Díaz Ramírez, Las tasas de interés en Colombia, Bogotá, Temis, 20 I4, 33, pp. I03 y I I 5-I 25. Cfr. también Ley 45 de I990, art. 72 .

Io6 Farina, Defensa del consumidor y del usuario, cit., pp. 402 y 403: "Para confundir al consumidor 
le permita al consumidor entenderlas para poder tomar una decisión informada de contratar o no contratar, caso en el cual serían ineficaces de pleno derecho.

La abusividad de las cláusulas que imponen el pago de intereses no autorizados por la ley tanto en los contratos de adhesión con consumidores como entre empresarios, estaría determinada más bien por los aspectos que se cobran al consumidor o adherente. De esta manera, la Corte Suprema de Justicia, interpretando el artículo 68 de la Ley 45 de I990, consideró ${ }^{107}$ :

... la disposición prohíbe el cobro de puntos relacionados con la inflación y el porcentaje de utilidades a que tiene derecho la entidad crediticia en desarrollo de su negocio, pues tales conceptos se entienden incluidos en la tasa de interés efectiva. Así mismo, los gastos por administración del crédito, manejo de cartera, papelería, en fin (...), que el concepto de tasa de interés efectiva comprende, también, la totalidad de los costos financieros a cargo del deudor vinculados al préstamo o relacionados con él. Igualmente, todo gasto que en desarrollo del crédito deba erogar la entidad bancaria, al margen de que lo justifique por "honorarios, comisiones u otros semejantes" (...), respecto de actividades relacionadas con microcréditos, como estudio de crédito, cuotas de administración o de manejo u otra equivalente, costos de operación, envío de extractos mensuales, expedición y manejo de cupones de pago, nómina, implementación y desarrollo de tecnologías, entre otros, por tratarse de rubros que se hacen en función y mejora de su objeto social.

Así las cosas, cuando el predisponente establece cláusulas de intereses cobrando alguno o algunos de estos rubros dentro de la tasa del interés que cobra al consumidor o adherente, estaremos frente a una cláusula abusiva.

\section{F. Cláusulas que obligan al adherente a acudir a la justicia arbitral}

Las partes de un contrato, sin importar que este sea negociado o de adhesión, pueden someter voluntariamente los conflictos que surjan a la decisión de árbitros, mediante una cláusula compromisoria o a través del compromiso, aunque para los propósitos de esta investigación nos concentraremos únicamente en la cláusula compromisoria.

y menoscabar sus derechos suele recurrirse a otro tipo de abuso: la utilización de cláusulas ambiguas que se prestan a diversas interpretaciones. Tales cláusulas muchas veces son oscuras o incompletas [...]. [I]mpone el deber jurídico de hablar claro, es decir, explicar concretamente a qué se obliga el estipulante y qué puede exigir el consumidor". Ley I 480 de 20 I I, arts. 26 y 37 .

I07 Corte Suprema de Justicia, Sala de Casación Civil, sentencia del I4 de diciembre de 20 I I, ref. C-I IOo I3 I030I 42000 I-or 489-or, M.P.: Jaime Alberto Arrubla Paucar. Cfr. Ley 45 de I990, art. 68. 
La cláusula compromisoria ha sido definida como "un acuerdo de voluntades mediante la cual las partes someten asuntos litigiosos futuros y eventuales que deriven de un contrato o estén relacionados con este a la decisión obligatoria de una o más personas privadas, conocidas como él o los árbitros" ${ }^{\circ}$.

Ahora bien, la jurisprudencia ${ }^{109}$ y la doctrina ${ }^{10}$ han entendido, de manera general para todos los contratos de adhesión, que la cláusula compromisoria es abusiva cuando tiene por objeto o como efecto limitar el acceso a la justicia del adherente por tratarse de un derecho que la ley reconoce en todas las personas, además de significar un aumento en los costos que debe asumir la parte débil para la protección de sus derechos, lo que genera un desestímulo para instaurar las acciones respectivas; pues no olvidemos que la justicia ordinaria es gratuita, mientas que la justicia arbitral es onerosa.

En relación con los contratos de adhesión con consumidores, las cláusulas compromisorias están expresamente prohibidas por el numeral I 2 del artículo 43 de la Ley I 480 de 20 I I, debido a que el legislador consideró que estas cláusulas eran abusivas por sí mismas; de manera que, en caso de ser incluidas por el predisponente en el contenido predispuesto, debían tenerse como ineficaces de pleno derecho por mandato expreso de la norma mencionada. Posteriormente se promulgó la Ley I 563 de 20 I 2 (Estatuto de Arbitraje) que en su artículo i i 8 deroga el numeral i 2 del artículo 43 de la Ley i 480 de 20 i r. Entonces, nos preguntamos, ¿son siempre eficaces las cláusulas compromisorias incluidas en los contenidos predispuestos de los contratos de adhesión con consumidores? La respuesta es no, porque la derogatoria que hizo el legislador no implica que sean siempre eficaces sin importar las circunstancias en que sean celebradas o incorporadas; lo que hizo el legislador simplemente fue someterlas a la valoración de abusividad que resulta de aplicar la cláusula abierta del artículo 42 de la Ley I480 de 20 I I, según la cual, en cada caso concreto, el juez deberá ponderar las

io8 Gabriel Correa Arango, De los principales contratos mercantiles, 2. a ed., Bogotá, Temis, i99i, p. I I9: "se trata de un contrato de carácter accesorio en virtud del cual, las partes acuerdan someter a la decisión de árbitros aquellas controversias o litigios que puedan surgir de una determinada relación contractual, a cuyo efecto se obligan a nombrar árbitros o a delegar su nombramiento a un tercero". Cfr. Ives DeraIns, Cláusulas compromisorias patológicas y combinadas, El contrato de arbitraje, reimpr. de la r. ${ }^{a}$ ed., Bogotá, Universidad del Rosario y Legis, 2008, p. I9I.

Io9 Corte Constitucional, Sala Plena, sentencia C-6o de 200 , M.P.: Carlos Gaviria Díaz: "los acuerdos entre particulares que restrinjan definitivamente el derecho de acceso a la justicia están proscritos constitucionalmente, ya sea que éstos prohíban de manera absoluta acudir a la justicia ordinaria o por medio de la imposición de sanciones o cargas desproporcionadas e irrazonables que imposibilitan el acceso a la jurisdicción”.

i io Ordoqui Castilla, Abuso del derecho, cit., p. 266: "La cláusula compromisoria por la que se deriva la resolución de conflictos a un tribunal puede ser abusiva según los casos pues ello puede suponer aumentar los costos procesales y limitar en la parte débil el acceso a la justicia. Además, en su regulación pueden existir abusos notorios cuando, por ejemplo, el tercer miembro en caso de discordia, lo elige el proponente". 
circunstancias que rodearon la celebración del contrato o la incorporación de la cláusula compromisoria. De esta manera, la intención del legislador fue darles a los contratos de adhesión con consumidores el mismo tratamiento legal que a las cláusulas compromisorias en los contratos de adhesión entre empresarios, toda vez que en ambos casos el juez tendrá que analizar en cada situación en particular si la cláusula compromisoria es abusiva o no, a partir del criterio mencionado.

\section{G. Cláusulas que restringen o eliminan la facultad del adherente para hacer efectivas frente al predisponente las garantías del producto}

En relación con los contratos de adhesión con consumidores, la Ley I 480 de 20 I I establece dos clases de garantía: la primera, la garantía legal, que tiene que darla todo productor respecto de los productos que fabrique y que, siendo nuevos (no usados), sean colocados en el mercado, otorgándose sobre la calidad, idoneidad y seguridad del producto, sin que sea permitido cobrar ninguna suma de dinero al consumidor por este concepto ${ }^{\text {II }}$. De manera que ningún producto nuevo puede carecer de garantía legal, y toda cláusula que esté dirigida a exonerar al productor de reconocer la garantía legal en los términos expuestos sería ineficaz de pleno derecho por mandato expreso del artículo 43 de la mencionada ley ${ }^{\mathrm{II}}$.

La segunda, es la garantía complementaria que el predisponente (productor, distribuidor, comercializador o expendedor) puede otorgar sobre los productos nuevos como una garantía adicional a la legal, y sobre la cual es permitido cobrar una suma de dinero al consumidor ${ }^{113}$, como por ejemplo, las garantías extendidas

i i I Carmen Ligia Valderrama Rojas, "De las garantías: una obligación del productor y el proveedor", en Perspectivas del derecho del consumo, Bogotá, Universidad Externado de Colombia, 201 3, p. 243: "la garantía es la obligación solidaria que tienen el productor y el proveedor de asegurarle al consumidor la calidad, idoneidad y el buen estado y funcionamiento de los bienes y servicios que ofrece en el mercado, para lo cual el Estatuto prevé un conjunto de mecanismos que pone a disposición del consumidor para exigir que dicha obligación se haga efectiva". Cfr. Mauricio Velandia Castro, "Acciones derivadas de las fallas en los productos (garantía legal, comercial y producto defectuoso)", en Perspectivas del derecho del consumo, cit., 508. Ley I 480 de $20 \mathrm{I}$ I, arts. 7, 8, 9, го у I I.

I 2 Superintendencia de Industria y Comercio, Oficina Asesora Jurídica, concepto n. ${ }^{\circ}$ I 3-I 7074 del I 3 de marzo de 20I3: "se encuentra prohibida la inclusión de cláusulas que tengan por efecto la limitación de los derechos legales de los consumidores, como lo son las garantías, por lo cual, una cláusula que reduzca o elimine el término de garantía legal de un bien o servicio será abusiva o ineficaz de pleno derecho".

i 3 Caycedo Espinel y Madriñán Rivera, Comentarios al nuevo estatuto del consumidor, Ley 480 de 201 I , cit., p. 56: "la garantía suplementaria [...] podrá ser otorgada por el productor, los comercializadores o terceros especializados que tengan la idoneidad para prestarla, siempre y cuando ésta mejore las condiciones de la garantía inicial. Debe constar por escrito, en lenguaje sencillo, de fácil lectura y comprensión. Esta garantía suplementaria podrá ser cobrada de forma adicional al precio del producto, pero en este caso deberá el consumidor conocer esta condición y aceptarla de forma expresa”. Cfr. Superintendencia de Industria y Comercio, Oficina Asesora Jurídica, concepto n. ${ }^{\circ}$ I 3-r 7074 del I 3 de marzo de 20 I 3: "la garantía suple- 
de los computadores. Así mismo, esta garantía complementaria puede ser ofrecida en la venta de productos usados, caso en el cual deberá informarse suficientemente al consumidor sobre el término de la garantía, los defectos que cubre y el costo de la misma, para que pueda tomar una decisión informada al respecto. Entonces, la eficacia de estas cláusulas dependerá de la información oportuna que se le dé al consumidor en relación con los aspectos antes mencionados.

Ahora bien, en tratándose de contratos de adhesión entre empresarios (no consumidores) se aplicarán los artículos 932 y 933 C.Co., que regulan la garantía de buen funcionamiento. En este sentido, la garantía de buen funcionamiento solamente deberá otorgarla el predisponente cuando así lo haya convenido de manera expresa o cuando venda cosas que por costumbre son vendidas con garantía de buen funcionamiento. Así mismo, la ley comercial da libertad al predisponente para fijar el tiempo de la garantía sobre los productos que vende, de manera que si guarda silencio al respecto, la ley suple ese vacío imponiendo un tiempo de vigencia de dos años a dicha garantía, que se contarán desde la fecha de perfeccionamiento del respectivo contrato. Por otra parte, en relación con el derecho que tiene el adherente de hacer efectiva la garantía de buen funcionamiento, la ley le otorga un plazo máximo de treinta días calendario para su ejercicio, contados a partir de la fecha en que conoció o debió conocer el defecto en el funcionamiento de la cosa adquirida.

\section{Conclusiones}

a) Dentro de los contratos de adhesión, la teoría de las cláusulas abusivas se erige en un mecanismo eficaz para preservar el equilibrio jurídico de los contratos de adhesión, mediante la restricción de la autonomía privada del predisponente, en especial cuando dichas cláusulas se encuentran prohibidas absolutamente en un listado taxativo contenido en la ley.

b) La teoría de las cláusulas abusivas es un mecanismo diseñado por el legislador para restablecer el equilibrio jurídico en los contratos de adhesión, cuando ha sido alterado significativamente por la incorporación de ciertas cláusulas en los contenidos predispuestos de esta clase de contratos, con el fin de privilegiar la satisfacción de los intereses del predisponente, maximizando así sus beneficios, a costa y/o en perjuicio de los intereses del adherente.

c) El control de contenido de las cláusulas abusivas en derecho colombiano no se encuentra consagrado en un único régimen jurídico, sino que, por el contrario, se halla dividido en uno de carácter especial y otro de carácter general. El primero de ellos está contenido en el Estatuto de 
Consumidor que, debido a su carácter especial, solamente será aplicable a los contratos de adhesión donde el adherente ostente la calidad de consumidor, entendido como destinatario final de los productos (bienes y/o servicios) adquiridos; dicho control especial le brinda a él una protección mayor y más eficiente de sus derechos a través de los mecanismos previstos por el legislador, a partir de figuras jurídicas e interpretaciones propias y diferentes a las contenidas en el régimen general. En tanto que el segundo se aplica a los contratos de adhesión entre empresarios, en donde el adherente carece de la calidad de consumidor, sometiendo toda discusión sobre la abusividad de una o algunas cláusulas al conocimiento del juez para que decida.

d) No toda cláusula predispuesta es abusiva. Solamente serán abusivas las cláusulas que, siendo contrarias a la buena fe, entrañan un desequilibrio jurídico relevante entre las obligaciones contraídas y los derechos adquiridos por cada contratante.

e) La aplicación de la teoría de las cláusulas abusivas en los contratos de adhesión con consumidores impone, en primer lugar, verificar que la cláusula se encuentra dentro del listado de las cláusulas prohibidas absolutamente, porque de ser así no podrá realizarse ninguna valoración judicial sobre su abusividad, siendo ineficaces de pleno derecho, en razón a que el legislador previamente las valoró y las consideró abusivas por sí mismas. Pero, si no se encuentra dentro de dicho listado, entonces su abusividad derivará de la cláusula abierta, que impone su valoración por el juez para determinar si es abusiva o no en consideración de las circunstancias existentes al momento de la celebración del contrato o de su inclusión en el contenido predispuesto del mismo. Este último criterio es el mismo que rige para la aplicación de la teoría de las cláusulas abusivas en los contratos de adhesión entre empresarios (o no consumidores).

\section{Bibliografía}

\section{Doctrina}

Alessandri, Arturo; Manuel Somarriva y Antonio Vodanovic. Tratado de derecho civil, partes preliminar y general, t. II, Santiago, Jurídica de Chile, I 998.

Alterini, Atilio Aníbal. Treinta estudios de derecho privado, Bogotá, Colección internacional n. ${ }^{\circ}$ I , Pontificia Universidad Javeriana, Temis, 20 I I .

Arrubla Paucar, Jaime Alberto. Contratos mercantiles, Teoría general del negocio mercantil, I a reimpr. de la I $3{ }^{\text {a }}$ ed., Bogotá, Legis, 20 I 3.

Ataz López, Joaquín y José Ramón Salelles Climent. "La libertad contractual y sus límites”, en Tratado de contratos, t. I, dir. Rodrigo Bercovitz RodríguezCano, Valencia, Tirant lo Blanch, 2009. 
Ballesteros Garrido, José Antonio. Las condiciones generales de los contratos y el principio de la autonomía de la voluntad, tesis doctoral dirigida por Dr. D. Julio Carbajo González, Barcelona, Bosch, I999.

Betti, Emilio. Teoría general del negocio jurídico, trad. A. Martín Pérez, Granada, Comares, 2008.

Betti, Emilio. Teoría general de las obligaciones, trad. José Luis de los Mozos, Madrid, Revista de Derecho Privado, i969.

Bianca, C. Massimo. Derecho civil, 3, El contrato, trad. Fernando Hinestrosa y Édgar Cortés, Bogotá, Universidad Externado de Colombia, 2007.

Branca, Giuseppe. Instituciones de derecho privado, 6. ${ }^{\mathrm{a}}$ ed., trad. Pablo Macedo, México, Porrúa, 1978.

Cárdenas Mejía, Juan Pablo. "Justicia y abuso contractual”, en Los contratos en el derecho privado, dirs. académicos Fabricio Mantilla Espinosa y Francisco Ternera Barrios, Bogotá, Colegio Mayor de Nuestra Señora del Rosario, Legis, 2007.

Cárdenas Mejía, Juan Pablo. "La protección del contratante y la evolución del derecho contemporáneo”, en Los contratos en el derecho privado, dirs. académicos Fabricio Mantilla Espinosa y Francisco Ternera Barrios, Bogotá, Colegio Mayor de Nuestra Señora del Rosario, Legis, 2007.

Correa Arango, Gabriel. De los principales contratos mercantiles, 2. a ed., Bogotá, Temis, I99I.

Cubides Camacho, Jorge. Obligaciones, 5. ${ }^{a}$ ed., Bogotá, Pontificia Universidad Javeriana, 2005 .

Castro y Bravo, Francisco de. Las condiciones generales de los contratos y la eficacia de las leyes, 2. ${ }^{\mathrm{a}}$ ed., Madrid, Civitas, 1985.

Cariota Ferrara, Luigi. El negocio jurídico, trad. Manuel Albaladejo, Madrid, Aguilar, I956.

De la Maza Gazmuri, Í̃̃igo. "Contratos por adhesión y cláusulas abusivas ¿Por qué el Estado y no solamente el mercado?”, Revista Chilena de Derecho Privado n. ${ }^{\circ}$ I, 2003.

De los Mozos, José Luis. "El contrato y sus transformaciones”, en Estudios de derecho civil, obligaciones y contratos, Libro homenaje a Fernando Hinestrosa, 40 años de rectoría I963-2003, t. I, Bogotá, Universidad Externado de Colombia, 2003.

De Solá Cañizares, Felipe. Tratado de derecho comercial comparado, t. i, Barcelona, Montaner y Simón, I963.

Delgado de Cantú, Gloria M. Historia universal, de la era de las revoluciones al

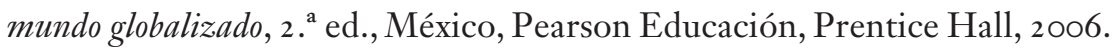


Derains, Ives. Cláusulas compromisorias patológicas y combinadas, El contrato de arbitraje, I. . reimpr. de la I. a ed., Bogotá, Universidad del Rosario, Legis, 2008.

Díaz Lindao, Indira. "Límites a las cláusulas modificativas de la responsabilidad en el derecho moderno de los contratos", Revista de Derecho Privado, Universidad Externado de Colombia, n. ${ }^{\circ} 23$, julio-diciembre de 20 I 2.

Díaz Ramírez, Enrique. Las tasas de interés en Colombia, Bogotá, Temis, 2014.

Farina, Juan M. Defensa del consumidor y del usuario, $3 .{ }^{a}$ ed., Buenos Aires, Astrea de Alfredo y Ricardo Depalma, 2004.

Farina, Juan M. Contratos comerciales modernos $1,3 .{ }^{a}$ ed., Buenos Aires, Astrea de Alfredo y Ricardo Depalma, 2005.

Fernández Allende, Manuel. "Contratos por adhesión y cláusulas abusivas, ilegales o inequitativas", en Defensa de los consumidores de productos y servicios, daños-contratos, dir. Gabriel Stiglitz, Buenos Aires, La Rocca, i 994.

Gil Echeverry, Jorge Hernán. "El abuso en las cláusulas contractuales”, en Estudios de derecho privado, Liber Amicorum en homenaje a Hernando Tapias Rocha, Bogotá, Universidad del Rosario, 20 I 3.

Giraldo lópez, Alejandro; Carlos Germán Caycedo Espinel y Ramón Eduardo Madriñán Rivera. Comentarios al nuevo estatuto del consumidor,

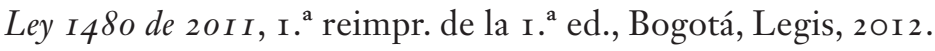

González de Alaiza Cardona, José Javier y Francisco Pertíñez Vílchez. "Los contratos de adhesión y la contratación electrónica”, en Tratado de contratos, t. iII, dir. Rodrigo Bercovitz Rodríguez-Cano, Valencia, Tirant lo Blanch, 2009.

Hellbroner, Robert L. La formación de la sociedad económica, 3. ${ }^{a}$ ed., México, Fondo de Cultura Económica, I974.

Hinestrosa, Fernando. Tratado de las obligaciones I, 2. a ed., Bogotá, Universidad Externado de Colombia, 2003.

Hinestrosa, Fernando. "De los principios generales del derecho a los principios generales del contrato”, Revista de Derecho Privado, Universidad Externado de Colombia, n. ${ }^{\circ}$ 5, 2000.

Josserand, Louis. Del abuso de los derechos y otros ensayos, Bogotá, Temis, i 999.

Larroumet, Christian. Teoría general del contrato, vol. i, reimpr. de la 2. ${ }^{\mathrm{a}}$ ed., trad. de Jorge Guerrero, Bogotá, Temis, I 999.

Lorenzetti, Ricardo Luis. "Tratamiento de las cláusulas abusivas en la ley de defensa del consumidor", Revista de Derecho Privado y Comunitario, n. ${ }^{\circ}$, Consumidores, Rubinzal-Culzoni.

Martínez Neira, Néstor Humberto. Cátedra de derecho bancario colombiano, 2. ${ }^{\text {a }}$ ed., Bogotá, Legis, 2004.

Messineo, Francesco. Doctrina general del contrato, t. I, trad. R. O. Fontanarrosa, S. Sentis Meledo y M. Volterra, Buenos Aires, Jurídicas Europa-América, I979. 
Mijailov, M. I. La revolución industrial, ro. ${ }^{a}$ reimpr., Bogotá, Panamericana, 20 I I.

Miranda Londoño, Alfonso. "Abuso de posición dominante: perspectivas de aplicación en Colombia a la luz del derecho comparado", Revista del Centro de Estudios del Derecho de la Competencia (CEDEC), Pontificia Universidad Javeriana, I997.

Mosset Iturraspe, Jorge. "Introducción al derecho del consumidor", Revista de Derecho Privado y Comunitario, n. ${ }^{\circ}$ 5, Consumidores, Rubinzal-Culzoni.

Ordoqui Castilla, Gustavo. Buena fe contractual, 2. a ed., Bogotá, Colección internacional n. ${ }^{\circ} 35$, Pontificia Universidad Javeriana, Universidad Católica del Uruguay, Grupo Editorial Ibáñez, 2012.

Ordoqui Castilla, Gustavo. Abuso del derecho, 2. ${ }^{\text {a }}$ ed., Bogotá, Colección internacional n. ${ }^{\circ}$ 20, Pontificia Universidad Javeriana, Grupo Editorial Ibáñez, 20 Io.

Ospina Fernández, Guillermo y Eduardo Ospina Acosta. Teoría general del contrato y del negocio jurídico, $7 .^{\text {a }}$ ed., Bogotá, Temis, 2005.

Ovalle Favela, José. "Los derechos de los consumidores", Revista de Derecho Privado, Universidad Nacional Autónoma de México, año Iv, n. ${ }^{\circ}$ I 2 , septiembre-diciembre de 2005 ,

Pagador López, Javier. "Condiciones generales y cláusulas abusivas", en La defensa de los consumidores y usuarios, dirs. Manuel Rebollo Puig y Manuel Izquierdo Carrasco, Madrid, Iustel, 20 I I.

Polo, Eduardo. Protección del contratante débil y condiciones generales de los contratos, Madrid, Civitas, I 990.

Posada Torres, Camilo. El equilibrio contractual en los contratos de adhesión, Bogotá, Grupo Editorial Ibáñez, 2014.

Rodríguez Azuero, Sergio. Contratos bancarios, su significación en América Latina, 2. reimpr. de la $6^{a}$ ed., Bogotá, Legis, 20 I 3.

Rodríguez Young, Camilo Andrés. Una aproximación a las cláusulas abusivas, Colección Precedentes jurisprudenciales, Bogotá, Legis, Universidad del Rosario, 2013.

Rengifo García, Ernesto. Del abuso del derecho al abuso de la posición dominante, reimpr. de la 2. a ed., Bogotá, Universidad Externado de Colombia, 2009.

Rengifo García, Ernesto. "Deber precontractual de información y las condiciones generales de contratación”, Revista de la Academia Colombiana de Jurisprudencia n. ${ }^{\circ} 327$, diciembre de 2004.

Roppo, Vincenzo. "Del contrato con el consumidor a los contratos asimétricos: perspectivas del derecho contractual europeo", Revista de Derecho Privado, Universidad Externado de Colombia, n. ${ }^{\circ}$ 20, enero-junio de 20 I I. 
Roppo, Vincenzo. El contrato de dos mil, trad. Milagros Koteich, Bogotá, Ensayos de la Revista de Derecho Privado n. ${ }^{\circ}$ I, Universidad Externado de Colombia, 2005 .

Rezzónico, Juan Carlos. Contratos con cláusulas predispuestas, condiciones negociales generales, Buenos Aires, Astrea de Alfredo y Ricardo Depalma, I987.

Salazar, Diego F. “Asimetrías de información y análisis económico de los contratos de adhesión: una reflexión teórica sobre el ejercicio de la libertad contractual”, Revista de Derecho Privado, Universidad de los Andes, n. ${ }^{\circ}$ 37, 2006.

Salazar Echeverri, Verónica María. "El control de las cláusulas abusivas en los contratos de adhesión con consumidores”, Opinión furídica, vol. io n. ${ }^{\circ}$ 20, Medellín, 20 I I.

Rinessi, Antonio Juan. Relación de consumo y derechos del consumidor, Buenos Aires, Astrea de Alfredo y Ricardo Depalma, 2006.

Serra Rodríguez, Adela. "Condiciones generales de la contratación y cláusulas abusivas celebrados con consumidores", Derecho Privado de Consumo, coord., María José Reyes López, Valencia, Tirant lo Blanch, 2005.

Soto Coaguila, Carlos Alberto y Jorge Mosset Iturraspe. El contrato en una economía de mercado, 2. ${ }^{\mathrm{a}}$ ed., Bogotá, Colección internacional n. ${ }^{\circ}$, Pontificia Universidad Javeriana, 2009.

Soto Coaguila, Carlos Alberto. "La transformación del contrato: del contrato negociado al contrato predispuesto", en Instituciones de Derecho Privado I, Contratación contemporánea, teoría general y principios, Lima y Bogotá, Palestra Editores y Temis, 2000.

Stiglitz, Rubén S. "Contrato de consumo y cláusulas abusivas”, Universitas n. o 93, Pontificia Universidad Javeriana, I997.

Stiglitz, Rubén S. y Gabriel Stiglitz. "Contratos, Parte general”, en Reformas al Código Civil n. ${ }^{\circ}$ 5, dirs. Atilio Aníbal Alterini y Roberto M. López Cabana, Buenos Aires, Abeledo-Perrot, i 994.

Suescún Melo, Jorge. Derecho privado, Estudios de derecho civil y comercial contemporáneo, t. II, 2. reimpr., Bogotá, Legis, 2005.

Valderrama Rojas, Carmen Ligia. "De las garantías: una obligación del productor y el proveedor”, en AA.vv., Perspectivas del derecho del consumo, Bogotá, Universidad Externado de Colombia, 20 I 3.

Vallespinos, Carlos Gustavo. El contrato por adhesión a condiciones generales, Buenos Aires, Editorial Universidad, r984.

Velandia Castro, Mauricio. "Acciones derivas de las fallas en los productos (garantía legal, comercial y producto defectuoso)", en AA.vv., Perspectivas del derecho del consumo, Bogotá, Universidad Externado de Colombia, 20 I 3.

Velandia Castro, Mauricio. Derecho de la competencia y el consumo, Bogotá, Universidad Externado de Colombia, 2008. 


\section{Normas jurídicas}

Constitución Política de la República de Colombia de r991.

Código Civil colombiano.

Código de Comercio colombiano.

Ley 45 del 18 de diciembre de 1990.

Ley I 480 , promulgada el I 2 de octubre de 20 I I.

\section{Jurisprudencia}

Corte Constitucional, Sala Plena, sentencia C-749 del 2 I de octubre de 2009, exp. D-7686, M.P.: Luis Ernesto Vargas Silva.

Corte Constitucional, Sala Sexta de Revisión, sentencia T-5 7 del 7 de julio de 2006, ref. T-1 308 I 25, M.P.: Marco Gerardo Monroy Cabra.

Corte Constitucional, Sala Plena, sentencia C-075 del 8 de febrero de 2006, exp. D-5747, M.P.: Rodrigo escobar Gil.

Corte Constitucional, Sala Plena, sentencia C-6I 6 del I 3 de junio de 200 I, exp. D-3279, M.P.: Rodrigo Escobar Gil.

Corte Constitucional, Sala Plena, sentencia C-I I4I del 30 de agosto de 2000, M.P.: Eduardo Cifuentes Muñoz.

Corte Constitucional, Sala Plena, sentencia C-6o del 24 de enero de 200 I, M.P.: Carlos Gaviria Díaz.

Corte Suprema de Justicia, Sala de Casación Civil, sentencia del 2 de febrero de 2001 , exp. 5670 , M.P.: Carlos Ignacio Jaramillo Jaramillo.

Corte Suprema de Justicia, Sala de Casación Civil, sentencia del i 9 de diciembre de 2005, exp. 1996-102 74, M.P.: César Julio Valencia Copete.

Corte Suprema de Justicia, Sala de Casación Civil, sentencia del 8 de septiembre de 20 I I, ref. I IO0 I-3 103-026-2000-043366-or, M.P.: William Namén Vargas.

Corte Suprema de Justicia, Sala de Casación Civil, sentencia del i 9 de octubre de 20 I I, exp. 200 I-00847, M.P.: William Namén Vargas.

Corte Suprema de Justicia, Sala de Casación Civil, sentencia del I4 de diciembre de 20 ir, ref. C-i Ioor 3 IO30I4200I-or 489-oi, M.P.: Jaime Alberto Arrubla Paucar.

\section{Laudos arbitrales}

Laudo Arbitral en Derecho, proferido el I de diciembre de 2006, Centro de Arbitraje y Conciliación de la Cámara de Comercio de Bogotá, árbitros: Carlos Esteban Jaramillo Scholls, Juan Pablo Cárdenas Mejía y Gabriel 
Jaime Arango Restrepo, demandante: Concelular S.A. (en liquidación), demandado: Comunicación Celular S.A., Comcel S.A.

Laudo Arbitral en Derecho, proferido el I 5 de noviembre de 2002, Centro de Arbitraje y Conciliación de la Cámara de Comercio de Bogotá, árbitros: Francisco Morales Casas (presidente), Sergio Muñoz Laverde y Roberto Uribe Ricaurte, demandante: Adriana María Calderón Palacio, demandado: Cafesalud Medicina Prepagada S.A.

\section{Conceptos}

Superintendencia de Industria y Comercio, Oficina Asesora Jurídica, concepto n. ${ }^{\circ}$ I 3 -I 7074 del I 3 de marzo de 2013. 